\title{
Trabajo en equipo y principio de confianza en el debate de la responsabilidad penal por mala praxis médica
}

\section{Teamwork and the Principle of Trust in the Debate on Criminal Liability for Medical Malpractice}

Liuver Camilo Momblanc* https://orcid.org/0000-0002-1311-095X

http://dx.doi.org/10.21503/lex.v19i27.2256

* Especialista de Posgrado en Derecho Penal y en Administración Pública. Profesor Auxiliar. Metodólogo de la Dirección de Organización, Planificación y Archivo. Vicerrectoría Primera. Universidad de Oriente. Ave. Patricio Lumumba, s/n, Altos de Quintero, Santiago de Cuba. Cuba. CP. 90500.

Correo electrónica: liuverc@uo.edu.cu

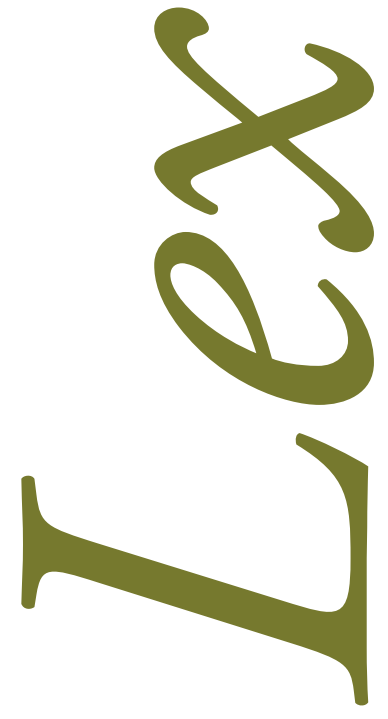




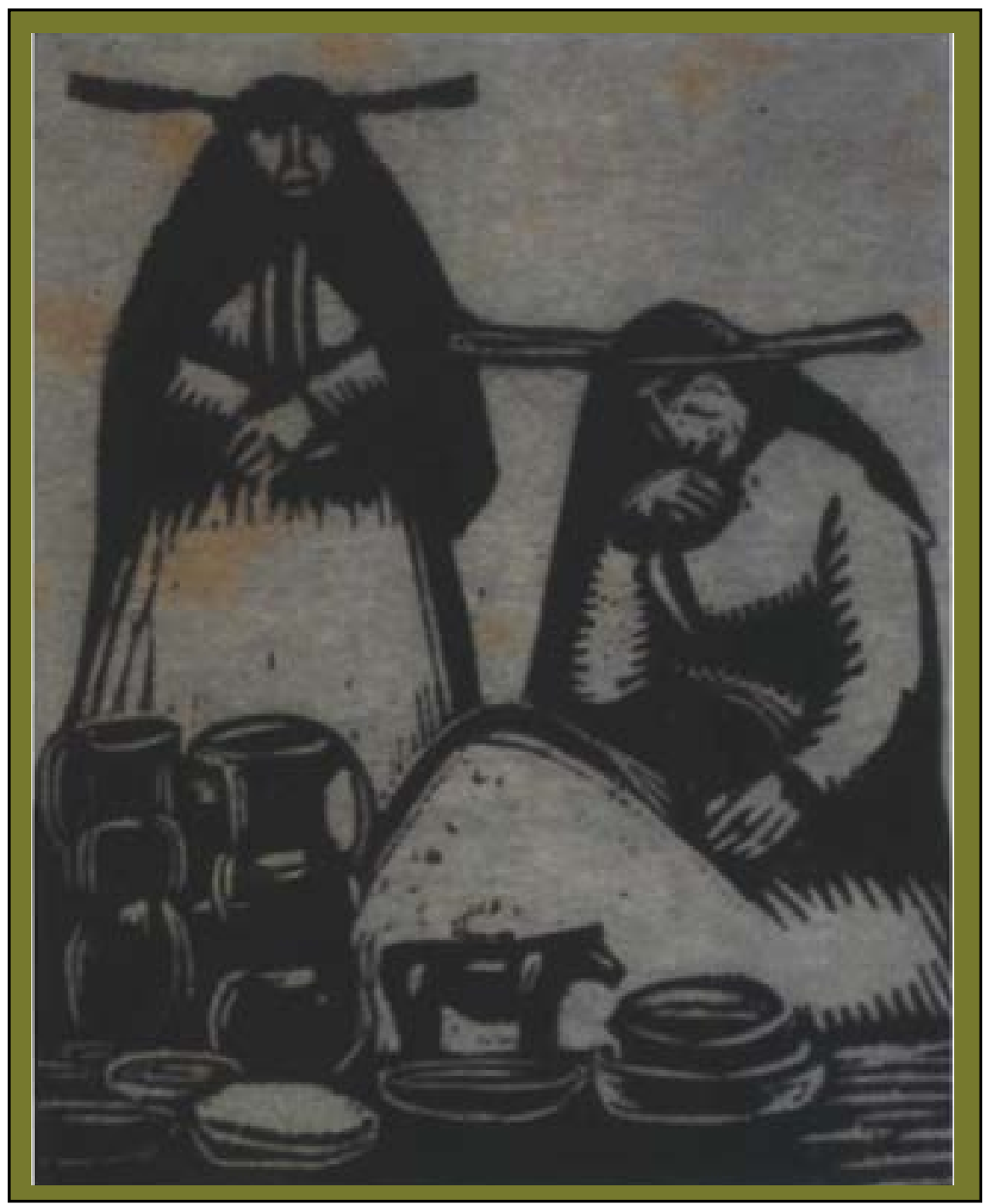

Cacharreras. José Sabogal pintor peruano del indigenismo (Cajabamba, Cajamarca, 1888-1957). 


\section{RESUMEN}

La complejidad de los procesos de responsabilidad médica en la actualidad requiere de iniciativas investigativas que brinden respuestas a los numerosos problemas que enfrentan los tribunales penales. En este sentido, la determinación de la responsabilidad penal imprudente en el marco de la ejecución de una actividad conjunta, como es el caso de los equipos médicos, constituye una de las cuestiones dogmáticas y prácticas necesitadas de una atención doctrinal. Con tales propósitos, este artículo tiene por objeto la realización de una breve sistematización de los presupuestos del principio de confianza como criterio válido para la delimitación de la responsabilidad penal en los casos de mala praxis o imprudencia médica en supuestos de actuación conjunta. También, sobre la base de estos postulados, se examina el ordenamiento jurídico-penal, la praxis médica y judicial cubana para indagar el estado de conocimiento y tratamiento de esta institución dogmática. Finalmente, se proponen un conjunto de pautas para la evaluación de la responsabilidad penal en los supuestos de aplicación del principio en la actuación médica.

Palabras clave: mala praxis médica, responsabilidad penal médica, principio de confianza.

\section{ABSTRACT}

The complexity of today's medical liability processes requires investigative initiatives that provide answers to the many problems facing the criminal courts. In this regard, the determination of imprudent criminal responsibility in the context of the execution of a joint activity, such as in the case of medical teams, constitutes one of the dogmatic and practical issues in need of doctrinal attention. With this in mind, the purpose of this article is to briefly systematize the assumptions of the principle of trust as a valid criterion for determining criminal liability in cases of medical malpractice or imprudence in cases of joint action. Also, based on these postulates, the $\mathrm{Cu}$ ban legal-criminal system and medical and judicial practice are examined in order to investigate the state of knowledge and treatment of this dogmatic institution. Finally, a set of guidelines is proposed for the evaluation of criminal responsibility in cases where the principle is applied in medical practice.

Key words: medical practice, medical criminal liability, principle of trust. 


\section{INTRODUCCIÓN}

La celeridad del desarrollo científico técnico junto a la complejidad de los diferentes objetos, fenómenos y procesos que son estudiados en la sociedad contemporánea impone una creciente especialización, incluso en los ámbitos de una misma rama del saber científico. Esto exige, cada vez más, la conformación de equipos interdisciplinarios para la investigación y solución de problemas profesionales. Una de los ámbitos donde mejor se ilustra esta dinámica es en la medicina, pletórica de especialidades, cuya praxis requiere la participación de diversos especialistas para la solución de un problema relacionado con la salud del paciente. En sus predios se escucha con frecuencia el concepto equipo médico para hacer referencia al conjunto de profesionales de la salud que intervienen en la ejecución de aquellos actos médicos generalmente complejos de los que las intervenciones quirúrgicas constituyen el clásico modelo. Esta práctica, si bien suele favorecer la eficacia de la actividad médica, complejiza la labor de discriminación de la responsabilidad en aquellos casos en que se produce un evento adverso con resultados lesivos para el paciente.

En el trabajo conjunto comúnmente existe una jerarquía y en términos generales un médico figura como jefe del equipo pero esto no significa que él o cualquier otro de los que participa deba responder por las negligencias de sus colegas o colaboradores. En este sentido la noción de autorresponsabilidad en sede penal permite destacar con claridad la idea de que nadie debe ser hecho responsable de un hecho ajeno o de una decisión contraria a las normas de un tercero. Dicho de otro modo, no forma parte del ámbito de responsabilidad de quien se comporta cuidadosamente impedir las consecuencias que resulten de la conducta descuidada de otro individuo. Igualmente, resulta político-criminalmente inaceptable que existiendo indicios -o incluso evidencias- del comportamiento imprudente del otro con quien se interactúa en una misma actividad, no se modifique la conducta con la finalidad de evitar el resultado lesivo al bien jurídico frente al incremento del riesgo jurídicamente desaprobado que se ha reconocido.

Cabe entonces reflexionar en torno a la nueva realidad que expresa la praxis médica determinada por la frecuente participación de una pluralidad de sujetos en la asistencia a un paciente y el reto jurídico que esta situación impone frente a resultados infaustos al momento de la determinación de la res- 
ponsabilidad difícilmente individualizable. ${ }^{1}$ Esto exige la formulación de pautas que faciliten delimitar dentro del equipo asistencial o de diagnóstico el alcance del ámbito de responsabilidad de cada uno de los integrantes. Dicho de otro modo, se trata de precisar la extensión del deber de cuidado que cada uno de los partícipes debe abarcar con su actuación; es decir, si además de los riesgos inherentes a la propia intervención debe tener en cuenta o no la conducta del tercero como si de un riesgo integrado a su ámbito competencial se tratase y en caso afirmativo cuándo inicia y hasta dónde llega tal deber. Con tales propósitos el principio de confianza ofrece una vía de solución para los supuestos de actuación conjunta diacrónica o sincrónica por lo cual se erige en importante herramienta dogmática que aplica a escenarios donde interactúan varios profesionales con reparto o división de funciones en el desarrollo de una actividad, entre los que se establecen relaciones horizontales y/o jerárquicas. ${ }^{2}$

Sobre este principio sólo encontramos en las publicaciones jurídicas de nuestro país una ponencia presentada en el Congreso Internacional Abogacía 2012 por los abogados RAMÍREZ COLLEJO y BLANCO FONSECA, ${ }^{3}$ quienes toman como referencia esencial las reflexiones desarrolladas por el profesor y abogado colombiano BERNATE OCHOA. ${ }^{4}$ Esto denota que ha estado prácticamente ausente del debate doctrinal en nuestro escenario académico lo que, como es natural, nos conduce a sostener que sobre este tópico, desde nuestras discusiones teóricas, aún no se predisponen mecanismos y reglas que orienten, según la perspectiva anunciada, la solución de conflictos penales.

A contrario sensu, una mirada a la producción científica internacional revela un respetable patrimonio bibliográfico en torno al principio de confianza como criterio orientador de la imputación en el contexto del trabajo en equipo con aplicación al ámbito médico. ${ }^{5}$ En consecuencia, este trabajo tiene

1 Cfr. Manuel Rivera Fernández, La responsabilidad médico-sanitaria y del personal sanitario al servicio de la administración pública (Valencia: Práctica del Derecho, 1997), 76. «La actuación médica ofrece hoy una complejidad extraordinaria. Cada día es más frecuente la realización del trabajo médico realizado en equipo, donde el diagnóstico o el tratamiento se hacen depender de una decisión plural asumida por varios facultativos. Esta nueva realidad, especialmente manifestada en la Cirugía, dificulta extraordinariamente, cuando acaece el daño, la determinación de la causa precisa y, dentro de ella, la posible concurrencia de comportamientos culposos. De alguna forma, la participación de una pluralidad de sujetos en la realización del acto médico, hace que la responsabilidad se diluya y sea difícilmente individualizable».

2 Jaime Lombana Villalba, Derecho Penal y responsabilidad médica (Colombia: Biblioteca Jurídica Diké, 2010), 266. «La complejidad de las relaciones sociales y la multiplicidad de situaciones en las cuales se presenta una división funcional de tareas ha motivado la existencia de principios que protejan el derecho a la autorresponsabilidad de los sujetos y eviten la imputación de actuaciones que correspondan a la esfera ajena, tal como sucede con el principio de confianza».

3 Yeline Ramírez Collejo y Ángel Antonio Blanco Fonseca, «La exigencia de responsabilidad penal en la actividad médica bajo el principio de confianza», en Abogacía y Derecho: Gestión de conflictos jurídicos, vol. I. Parte. Derecho y litigios penales (La Habana: Ediciones ONBC, 2012), 20-40.

4 Francisco Bernate Ochoa, «Responsabilidad penal médica, trabajo en equipo y principio de confianza», Prolegómenos: derechos y valores XI, n.o 21 (junio de 2008): 65-80.

5 Sobre el principio de confianza y su aplicación al ámbito de la responsabilidad médica, entre otros: Mario Maraver Gómez, «El principio de confianza en el Derecho Penal. Un estudio sobre la aplicación del principio de autorresponsabilidad en la teoría de la imputación objetiva» (Tesis doctoral, Universidad Autónoma de Madrid, 2007); Mario Maraver Gómez, El principio de confianza en el Derecho penal. Un estudio sobre la aplicación del principio de autorresponsabilidad 
por objeto la realización de una breve sistematización de los presupuestos del principio de confianza como criterio válido para la delimitación de la responsabilidad penal en los casos de mala praxis o imprudencia médica con la intervención de varios sujetos. Sobre la base de estos postulados, se examina luego el ordenamiento jurídico-penal, la praxis médica y judicial en Cuba para indagar el estado de conocimiento y tratamiento de esta institución dogmática. Finalmente, se proponen un conjunto de pautas para la evaluación de la responsabilidad penal en los supuestos de aplicación del principio en la actuación médica. Todo lo anterior en procura de promover un debate que contribuya a su desarrollo teórico y jurisprudencial en nuestro escenario en aras de su adopción como herramienta para la determinación de la responsabilidad penal por mala praxis médica cuando la afectación a la vida o salud psicofísica del paciente se produce en el marco del trabajo en equipo.

\section{DIVISIÓN DEL TRABAJO Y TRABAJO EN EQUIPO EN EL ÁMBITO MÉDICO. UN PREÁMBULO NECESARIO}

Es un hecho notorio que la actividad médica se configura bajo el criterio de la división de funciones como forma de organizar y ejecutar el trabajo sin el que hoy sería difícil entender la medicina. Desde hace algún tiempo el ejercicio de la medicina ha dejado de ser una actividad caracterizada por la exclusiva relación entre el paciente y su denominado médico de cabecera. Lo común, incluso en los tratamientos más sencillos, es que el médico se sirva de la ayuda de un tercero, ya sea otro galeno, una enfermera o cualquier otro personal auxiliar. No es por ello de extrañar que existan propuestas doctri-

en la teoría de la imputación objetiva (Cizur Menor: Civitas, 2009); María del Carmen Gómez Rivero, La responsabilidad penal del médico (Valencia: Tirant lo Blanch, 2003), 394-440; Bernate Ochoa, «Responsabilidad penal médica, trabajo en equipo y principio de confianza»; Francisco Bernate Ochoa, Imputación objetiva y responsabilidad penal médica (Bogotá: Universidad del Rosario, 2010), 160-81; Virgilio Rodríguez Vázquez, «La delimitación de la responsabilidad penal en el equipo médico-sanitario. Operatividad del principio de confianza ante la división del trabajo sanitario», accedido 21 de diciembre de 2017, http://www.aeds.org/congreso/congresos-aeds/ponencias/Virgilio\%20Rodriguez\%20 Vazquez.pdf; Virgilio Rodríguez Vázquez, Responsabilidad penal en el ejercicio de actividades médico-sanitarias. Criterios para delimitar la responsabilidad en supuestos de intervención conjunta de los profesionales sanitarios (Madrid: Marcial Pons, 2012), 183-300; José María Peláez Mejía, «Configuración del "principio de confianza" como criterio negativo de tipicidad objetiva», Revista Prolegómenos Derechos y Valores 19, n.o 37 (junio de 2016): 15-35, doi:http://dx.doi. org/10.18359/prole.1677; Agustín Jorge Barreiro, La imprudencia punible en la actividad médico-quirúrgica (Madrid: Tecnos, 1990); Geovana Andrea Vallejo Jiménez, «Responsabilidad penal sanitaria: problemas específicos en torno a la imprudencia médica» (Tesis doctoral, Universidad de León, 2012), 163-94, https://buleria.unileon.es/bitstream/handle/10612/2217/tesis_e4242b.pdf?sequence=1; José Ángel Fernández Cruz, «El delito imprudente: la determinación de la diligencia debida en el seno de las organizaciones», Revista de Derecho XIII (2002): 101-21; Bernardo Feijoo Sánchez, «El principio de confianza como criterio normativo de imputación en el Derecho penal: fundamento y consecuencias dogmáticas», Revista de Derecho Penal y Criminología 21, n.o 69 (junio de 2000): 37-76; Carlos María Romeo Casabona, El Médico y el Derecho Penal, vol. I (Santa Fe: Rubinzal-Culzoni, 2011), 284 ss; Lucia Risicato, Lattività medica di équipe tra affidamento e obblighi di controllo reciproco. L'obbligo di vigilare come regola cautelare (Torino: Giappichelli, 2013); Lautaro Contreras, «El principio de confianza como criterio delimitador de la responsabilidad penal de los médicos», Acta Bioethica 25 (2019); Andrea Perin, «Estandarización y automatización en medicina: El deber de cuidado del profesional entre la legítima confianza y la debida prudencia», Revista Chilena de Derecho y Tecnología 8, n.o 1 (2019): 15-17, doi:10.5354/0719-2584.2019.52560. 
nales que inviten a sustituir la tradicional denominación de «relación médico-paciente» que sugiere la idea de un vínculo bipolar por la de «relación clínica» o "relación sanitaria». ${ }^{6}$ En este contexto el principio de división del trabajo, utilizado en diversas disciplinas científicas, también alcanza los predios del Derecho penal y su estudio ofrece pautas para determinar el deber de cuidado primario de cada uno de los participantes en el acto médico respecto a la actuación realizada en forma conjunta.

Existe unanimidad en la doctrina al entender que la división horizontal del trabajo supone interacción de los partícipes en una relación de igualdad, mientras que en la organización vertical impera un principio de jerarquía que establece relaciones de supra-subordinación. ${ }^{7}$ En este último supuesto, se entiende que unos profesionales están obligados a seguir las indicaciones de sus superiores, y estos tienen el derecho de emitir esas órdenes y la obligación correlativa de cumplir con los deberes complementarios inherentes a su cargo. Sin embargo, el consenso desaparece al momento de precisar el criterio que permite calificar como horizontal o vertical una relación de trabajo en la actuación médica. Básicamente, de acuerdo con VALLEJO JIMÉNEZ, ${ }^{8}$ encontramos un sector mayoritario que sostiene la diferenciación en el criterio de la formación profesional. ${ }^{9}$ Otro sector considera que la distinción obedece a la asignación de competencias funcionales entre los intervinientes ${ }^{10} \mathrm{y}$ un último grupo, con una posición intermedia, defiende acudir a ambos criterios, ${ }^{11}$ porque por sí solos -como revelan las críticas

6 José Lázaro y Diego Gracia, «La nueva relación clínica», 2003, 9, https://docenciabasurto.osakidetza.net/pluginfile. php/9595/mod_folder/content/0/Nueva\%20relacion\%20clinica.pdf?forcedownload=1. Cfr. Diego Gracia, Ética y vida No 2: Bioética Clínica (Santa Fé de Bogotá: Editorial El Búho, 1998), 66-67; Diego Gracia, «Introducción a la bioética médica», Boletín de la Oficina Sanitaria Panamericana 108, n.o 5 y 6 (junio de 1990): 377-78; Jesús Armando Martínez Gómez, «Naturaleza jurídica de la relación médico-paciente. Estado de la cuestión en Cuba» Bioética (agosto de 2013): 6.

7 Vid. Gómez Rivero, La responsabilidad penal del médico, 395; Rodríguez Vázquez, Responsabilidad penal en el ejercicio de actividades médico-sanitarias. Criterios para delimitar la responsabilidad en supuestos de intervención conjunta de los profesionales sanitarios, 188; Vallejo Jiménez, «Responsabilidad penal sanitaria: problemas específicos en torno a la imprudencia médica», 143 y ss; Jorge Barreiro, La imprudencia punible en la actividad médico-quirúrgica, 116; Jesús María Silva Sánchez, Medicinas alternativas e imprudencia médica (Barcelona: José María Bosch Editor, 1999), 27 y ss; Antonio Choclán Montalvo, Deber de cuidado y delito imprudente (Barcelona: Bosch, 1998), 106; Esther Hava García, La imprudencia médica (Valencia: Tirant lo Blanch, 2001), 76 y ss; Carolina Villacampa Estiarte, Responsabilidad penal del personal sanitario. Atribución de responsabilidad penal en tratamientos médicos efectuados por diversos profesionales (Pamplona: Aranzadi, 2003), 149 y ss; Javier De Vicente Remesal y Virgilio Rodríguez Vázquez, «El médico ante el Derecho penal: consideraciones sobre la imprudencia profesional, inhabilitación profesional y el trabajo en equipo», en Universitas vitae. Homenaje a Ruperto Núñez Barbero, ed. Fernando Pérez Álvarez (Salamanca, España: Ediciones Universidad de Salamanca, 2007), 170.

8 Vallejo Jiménez, «Responsabilidad penal sanitaria: problemas específicos en torno a la imprudencia médica», 144.

9 Vid. Jorge Barreiro, La imprudencia punible en la actividad médico-quirúrgica, 116; Bernardo Feijoo Sánchez, Homicidio y lesiones imprudentes: Requisitos y límites materiales (Zaragoza: Edijus, 1999), 232; Hava García, La imprudencia médica, 76; Gómez Rivero, La responsabilidad penal del médico, 395.

10 Villacampa Estiarte, Responsabilidad penal del personal sanitario. Atribución de responsabilidad penal en tratamientos médicos efectuados por diversos profesionales, 156. En la doctrina alemana: Bockelmann, Umbreit, Brose, Bergmann, referenciados en: Rodríguez Vázquez, Responsabilidad penal en el ejercicio de actividades médico-sanitarias. Criterios para delimitar la responsabilidad en supuestos de intervención conjunta de los profesionales sanitarios, 196, $n$. 26.

11 Carlos Romeo Casabona, El médico y el Derecho penal I. La actividad curativa (Licitud y responsabilidad penal) (Bar- 
de las que han sido objeto- son insuficientes para explicar tal clasificación. ${ }^{12}$

Conforme al criterio de la formación profesional, quienes se encuentren en el mismo nivel de preparación académica o de cualificación en sus respectivas ramas (v.gr., cirujano, anestesista), se hallarán en una forma de división horizontal de trabajo, ${ }^{13}$ y quienes posean niveles de formación diferentes (v.gr., cirujano, instrumentador quirúrgico, técnico en enfermería), bajo una actuación jerarquizada propia de las funciones verticales. Dentro de esta postura, además de la identificación del nivel formativo con titulación académica algunos autores incluyen el elemento del conocimiento adquirido a través de la experiencia laboral. Los que fundamentan el criterio clasificador solo en la titulación académica asumen una postura restrictiva o formal; en tanto, los segundos, entienden la formación en un sentido mucho más amplio, o sea, material. ${ }^{14}$ Según sea la vertiente adoptada la relación existente entre dos profesionales con idéntica titulación podrá ser calificada solo de horizontal o, en determinados casos, de vertical. ${ }^{15}$

Los partidarios del segundo criterio, consideran que tales argumentos resultan insuficientes para la determinación del carácter de las relaciones que se establecen en este sector de actividad. Las estructuras hospitalarias contemporáneas, debido al progreso de la medicina, son concebidas como organizaciones complejas y diversificadas, obligadas a crear divisiones organizacionales de orden: directivo, de gestión, científico y técnico. Su modo de operar se diseña a través de organigramas funcionales donde cada dirección tendrá asignada una competencia ${ }^{16}$ y se debe acudir al reparto competencial u organigrama funcional establecido en la institución como criterio de clasificación porque este no siempre depende de la cualificación profesional. Puede ocurrir que profesionales con la misma titulación académica y formación, se encuentren en un diferente plano jerárquico e incluso que no siempre el médico ocupe una posición superior respecto del que no lo es (v. gr. personal de enfermería). ${ }^{17}$

celona: Bosch, 1981), 250; Villacampa Estiarte, Responsabilidad penal del personal sanitario. Atribución de responsabilidad penal en tratamientos médicos efectuados por diversos profesionales, 156-58; Rodríguez Vázquez, Responsabilidad penal en el ejercicio de actividades médico-sanitarias. Criterios para delimitar la responsabilidad en supuestos de intervención conjunta de los profesionales sanitarios, 396.

12 Rodríguez Vázquez, Responsabilidad penal en el ejercicio de actividades médico-sanitarias. Criterios para delimitar la responsabilidad en supuestos de intervención conjunta de los profesionales sanitarios, 198.

13 Sostiene Gómez Rivero que «(...) asumen con el mismo grado de responsabilidad las respectivas fases del tratamiento»., Gómez Rivero, La responsabilidad penal del médico, 395.

14 Vid. Jorge Barreiro, La imprudencia punible en la actividad médico-quirúrgica, 115 y ss. Asimismo, Wilhem, referenciado en: Rodríguez Vázquez, Responsabilidad penal en el ejercicio de actividades médico-sanitarias. Criterios para delimitar la responsabilidad en supuestos de intervención conjunta de los profesionales sanitarios, 189, n. 12.

15 Cfr. Rodríguez Vázquez, Responsabilidad penal en el ejercicio de actividades médico-sanitarias. Criterios para delimitar la responsabilidad en supuestos de intervención conjunta de los profesionales sanitarios, 189.

16 Ibid., 198-99; Vallejo Jiménez, «Responsabilidad penal sanitaria: problemas específicos en torno a la imprudencia médica», 153.

17 Cfr. Rodríguez Vázquez, Responsabilidad penal en el ejercicio de actividades médico-sanitarias. Criterios para delimitar la responsabilidad en supuestos de intervención conjunta de los profesionales sanitarios, 189 y ss. 
De igual modo, según esta opinión, en más de una ocasión se verá que entre médicos y enfermeras no existe, dentro del organigrama de la institución una relación de supra-subordinación que pueda fundamentar el derecho a dar órdenes a uno de ellos y la obligación del otro de cumplirlas. En este tenor se entiende que se encuentran en un mismo plano estructural cuyo campo competencial de un profesional respecto al otro es autónomo. También ocurre que existen actos médicos que requieren de otros para su realización planteándose entre ellos una relación de dependencia como sucede entre especialidades terapéuticas y especialidades diagnósticas que son instrumentales de aquéllas. Sin embargo, esta situación no significa que una especialidad sea superior jerárquicamente a la otra, ya que las funciones entre una y otra esfera están claramente delimitadas, y permanecen como ámbitos exclusivos de intervención para sus respectivos actores. ${ }^{18}$ Algunos autores opinan que las funciones del personal auxiliar pueden ser consideradas autónomas respecto a las realizadas por los médicos hasta establecerse entre ellos una relación de horizontalidad. ${ }^{19}$ Sin embargo, siendo posible que en la concreta distribución de funciones el titulado de inferior categoría asuma competencias autónomas, esa autonomía será siempre relativa porque en la mayoría de las ocasiones los no facultativos actúan por indicación expresa del médico encargado de la terapia o tratamiento del paciente. ${ }^{20}$

Otra cuestión discutida en este marco es la relativa a la delegación de funciones respecto a la cual existen autores que entienden que la división vertical del trabajo y delegación son sinónimas y pueden utilizarse indistintamente. ${ }^{21}$ Para otros, la delegación es una modalidad de la división vertical del trabajo, pero esta última no implica necesariamente la primera, es decir, no siempre que se hable de división de funciones se podrá identificar con casos de delegación; $;^{22}$ en tanto un tercer grupo considera que división vertical y delegación son aspectos diferentes que no se deben confundir. ${ }^{23}$ En este debate se coincide con RODRÍGUEZ VÁZQUEZ, cuando expresó que: "si bien es cierto que la delegación no implica formalmente que exista una relación jerárquica entre ambos sujetos, materialmente va a suponer que un sujeto se vea obligado a ejercer algún tipo de vigilancia o control sobre otros. Es decir, de hecho, se produce el nacimiento de una relación vertical". ${ }^{24}$

18 Cfr. Ibid., 195; Vallejo Jiménez, «Responsabilidad penal sanitaria: problemas específicos en torno a la imprudencia médica», 149 y ss.

19 Villacampa Estiarte, Responsabilidad penal del personal sanitario. Atribución de responsabilidad penal en tratamientos médicos efectuados por diversos profesionales, 156 y ss.

20 Rodríguez Vázquez, Responsabilidad penal en el ejercicio de actividades médico-sanitarias. Criterios para delimitar la responsabilidad en supuestos de intervención conjunta de los profesionales sanitarios, 202-8, 213.

21 Silva Sánchez, Medicinas alternativas e imprudencia médica, 28; Choclán Montalvo, Deber de cuidado y delito imprudente, 106; Gómez Rivero, La responsabilidad penal del médico, 428.

22 Jorge Barreiro, La imprudencia punible en la actividad médico-quirúrgica, 116.

23 Villacampa Estiarte, Responsabilidad penal del personal sanitario. Atribución de responsabilidad penal en tratamientos médicos efectuados por diversos profesionales, 156 y ss.

24 Rodríguez Vázquez, Responsabilidad penal en el ejercicio de actividades médico-sanitarias. Criterios para delimitar la responsabilidad en supuestos de intervención conjunta de los profesionales sanitarios, 197. Cfr. Vallejo Jiménez, «Responsabilidad penal sanitaria: problemas específicos en torno a la imprudencia médica», 155-58. 
Un supuesto que ha merecido la atención de la doctrina es el de la relación entre el médico residente y su tutor respecto al cual se revela una viva polémica sobre la consideración de si efectivamente se produce entre ellos una relación vertical. Para la mayoría, ${ }^{25}$ no existe duda de esta, pero otros la excluyen del ámbito propio de la división del trabajo. ${ }^{26}$ También en este debate, le asiste razón a RODRÍGUEZ VÁZQUEZ, cuando plantea que la relación que media entre el residente y su tutor debe incluirse en los supuestos propios de la división vertical de funciones, ya que cumple con las características propias de esta forma de organizar el trabajo, es decir, una función dependiente de otra. Se trata de unas espéciales obligaciones de uno de ellos respecto al otro pero sin que se pueda llegar a afirmar que se anule cierto ámbito de competencia del residente aunque sea mínimo, por lo que califica como una relación de delegación. ${ }^{27}$

Como solución final el criterio inicial que se debe tener en cuenta para calificar una relación de horizontal o vertical en el contexto médico es el de la formación de los intervinientes en un sentido estricto, restrictivo o formal por corresponderse con la práctica médica y por razones de seguridad jurídica. La vertiente material de este criterio siempre estaría dotada de cierta carga de subjetividad. Por otra parte, no es poco frecuente en este ámbito la inexistencia de regulaciones precisas al respecto, sobre todo aquellas que establecen como se relacionan los profesionales en función de sus niveles competenciales, quedando en manos de los centros asistenciales o de los propios profesionales la regulación de tales competencias y relaciones. Frente a esta realidad en la determinación de las competencias que corresponden a cada uno de los profesionales que intervienen en el tratamiento del paciente, o sea, para saber qué es lo que corresponde a cada profesional y cómo puede ser su relación con otros profesionales, por lo menos como punto de partida, el más viable es el de la formación académica y en una línea más estricta el criterio de la titulación. No obstante, no se puede olvidar que por razones de posición en el organigrama, sujetos con idéntica titulación pueden encontrarse en planos jerárquicos diferentes. Por tanto, consideramos necesario complementar el criterio de la formación académica con el criterio de la posición en el organigrama cuando esta pueda afectar a la competencia profesional de los intervinientes para poder determinar cuando la división del trabajo es horizontal o vertical, lo cual ha de comprobarse en cada caso concreto.

Realizado este recorrido aún queda por cuestionarse si toda actividad médica se puede encuadrar bajo el modelo de organización laboral de la división de trabajo. Según RODRÍGUEZ VÁZQUEZ, la

25 Hava García, La imprudencia médica, 84; Agustín Jorge Barreiro, «Nuevos aspectos de la imprudencia jurídico-penal en la actividad médica: la culpa en el equipo médico-quirúrgico», en Responsabilidad del personal sanitario (Actas del Seminario conjunto sobre la responsabilidad del personal sanitario celebrado en Madrid los días 14, 15 y 16 de noviembre de 1994) (Madrid: Consejo General del Poder Judicial, 1995), 383; Vallejo Jiménez, «Responsabilidad penal sanitaria: problemas específicos en torno a la imprudencia médica», 160-62.

26 Así, Gómez Rivero, La responsabilidad penal del médico, 404-5.

27 Rodríguez Vázquez, Responsabilidad penal en el ejercicio de actividades médico-sanitarias. Criterios para delimitar la responsabilidad en supuestos de intervención conjunta de los profesionales sanitarios, 214. 
existencia de una pluralidad de intervinientes en una misma actividad constituye la condición necesaria. La condición suficiente es que exista un plan común. Esto último es característico de este ámbito porque aun cuando apreciamos intervenciones autónomas, siempre formarán parte de un plan común que tiene al paciente y su salud como puntos de referencia. ${ }^{28}$

El otro punto a dilucidar es el relativo a la determinación de cuándo esa división del trabajo se da en el marco del trabajo en equipo. Sobre todo por la confusión que ha generado la indistinta utilización de términos como trabajo en equipo, equipo médico, trabajo en grupo, entre otras. También se debate si este se configura solo en las actuaciones simultáneas u opera también en actuaciones sucesivas. En síntesis, se puede afirmar que el trabajo en equipo es una forma de organizar el trabajo que, además de reunir las caracterizas propias de la división del trabajo, supone una ordenación de las actividades de cada uno de los intervinientes, lo que exige una organización premeditada, puesta en común de los diferentes profesionales sobre las actuaciones que se van a seguir en relación con un concreto paciente. ${ }^{29}$

Los equipos de trabajo son apropiados sobre todo para llevar a cabo tareas de alto nivel de complejidad como, por lo general, acontece en la medicina. Este trabajo en equipo exige que los diversos miembros que intervienen en la asistencia al paciente lo hagan de forma conjunta y coordinada bajo la dirección y supervisión, al menos, de uno ellos. En este escenario grupal ha de lograrse, conforme asevera GÓMEZ RIVERO, ${ }^{30}$ que la actividad de cada uno se realice de forma correcta y articule con la del resto. Cada uno debe funcionar como los distintos engranajes de un único proceso terapéutico. Solo así puede garantizarse, si no la curación, sí la conformidad de la terapia con las reglas de la lex artis. ${ }^{31}$

Al tratarse de un término con diferentes acepciones, existen muchas definiciones de equipo cuyo significado varía en función al contexto. En este caso comprende el grupo de dos o más profesionales de la salud que unidos con un objetivo común (la curación del enfermo) intervienen en un acto médico. ${ }^{32}$ Un grupo en sí mismo necesariamente no significa un trabajo conjunto ni la participación de una pluralidad de profesionales de la medicina siempre supone la existencia de un equipo. ${ }^{33}$

\section{Ibid., 25}

29 Ibid., 257; Vallejo Jiménez, «Responsabilidad penal sanitaria: problemas específicos en torno a la imprudencia médica», 141-44.

30 Gómez Rivero, La responsabilidad penal del médico, 394-95.

$31 \mathrm{El}$ arte médico o lex artis es una de las categorías centrales de cualquier debate asociado a la evaluación de la responsabilidad ética o jurídica del facultativo. La generalidad de los textos que abordan estos temas se refieren a ella como el conjunto de normas y procedimientos adoptados en diversos documentos, guías de buenas prácticas, manuales y protocolos que deben observar los médicos en el desempeño profesional. A partir de su evaluación se juzga si el acto médico desarrollado por el facultativo es o no correcto o se ajusta o no a lo que debe hacerse.

32 Bernate Ochoa, «Responsabilidad penal médica, trabajo en equipo y principio de confianza», 70.

33 Existe en el ejercicio de la medicina varios supuestos de colaboración que suponen una participación de una pluralidad de profesionales pero no un trabajo en equipo. Así ocurre, por ejemplo, en las remisiones de paciente y cuando se encargan pruebas, aunque en este caso una actitud negligente del laboratorio que condiciona todo el proceso del cual el médico principal no tiene la capacidad de percatarse, la responsabilidad de éste último podría excluirse en aplicación de la teoría de la prohibición de regreso. Pero en general, en estos supuestos en los que realmente no existe una cooperación con división del trabajo, en los cuales los diversos componentes trabajan de forma conjunta y coordinada, bajo la dirección de uno de ellos, el médico encargado del paciente sigue siendo el responsable de su salud. Cfr. Lombana Villalba, Derecho Penal y responsabilidad médica, 269-70. 
Son varias las exigencias y su conformación en el ámbito médico está condicionada por la especialización de tareas, conocimientos o complejidad del acto que debe ejecutarse. A nuestro juicio constituyen sus invariantes: "la existencia de una pluralidad de profesionales de la salud (dos o más) con la misma o diferente titulación, la definición de roles y distribución de tareas específicas a sus miembros, concreción de relaciones jerárquicas y horizontales, y la aportación coordinada de todos los integrantes a la ejecución del acto médico". Ahora bien, no resulta ocioso aclarar que aunque la mayoría de los supuestos y desde luego, los que no ofrecen dudas en su calificación como tal son aquellos en los que las intervenciones se producen simultáneamente, como en el clásico ejemplo de "Team quirúrgico", estas características también se pueden dar en intervenciones sucesivas. ${ }^{34}$

La relevancia jurídica de estos criterios al momento de la determinación de la responsabilidad penal de los miembros del equipo médico por la infracción del deber de cuidado radica en los siguientes postulados. Aquellos que se encuentran en un plano horizontal asumen con el mismo grado de responsabilidad las respectivas fases del tratamiento, por lo que el punto de partida será el de la responsabilidad propia e individual de cada especialista. ${ }^{35}$ A contrario sensu, en el marco de las relaciones verticales emerge a un primer plano el deber del subordinado jerárquico, sin perjuicio de la responsabilidad en que pueda haber incurrido el superior por faltar a su especiales deberes secundarios de vigilancia, control o supervisión. Sin embargo, como asevera VALLEJO JIMÉNEZ, ${ }^{36}$ estos criterios por sí solo no son suficientes ni determinantes a la hora de precisar la responsabilidad de los miembros del equipo de trabajo. En su conjunto constituyen una primera aproximación o fundamento para establecer los límites o alcance del principio de confianza en el marco del trabajo en equipo como criterio de imputación, a los efectos de determinar sobre quién o quiénes, debe recaer la responsabilidad penal.

\section{LA GÉNESIS DEL PRINCIPIO DE CONFIANZA. SU GENERALIZACIÓN COMO INSTRUMENTO DOGMÁTICO}

La doctrina mayoritaria atribuye a la jurisprudencia alemana de la década del treinta del siglo XX la formulación del principio de confianza asociado al tráfico viario con aplicación al Derecho penal de la circulación. ${ }^{37}$ De esta forma la opinión dominante deja ver que se trata de un principio de creación

34 Rodríguez Vázquez, Responsabilidad penal en el ejercicio de actividades médico-sanitarias. Criterios para delimitar la responsabilidad en supuestos de intervención conjunta de los profesionales sanitarios, 258.

35 Cfr. Jorge Barreiro, La imprudencia punible en la actividad médico-quirúrgica, 138; Gómez Rivero, La responsabilidad penal del médico, 395; Vallejo Jiménez, «Responsabilidad penal sanitaria: problemas específicos en torno a la imprudencia médica», 148.

36 Vallejo Jiménez, «Responsabilidad penal sanitaria: problemas específicos en torno a la imprudencia médica», 162.

37 Vid. Maraver Gómez, «El principio de confianza en el Derecho Penal. Un estudio sobre la aplicación del principio de autorresponsabilidad en la teoría de la imputación objetiva», 7 ss; De Vicente Remesal y Rodríguez Vázquez, «El médico ante el Derecho penal: consideraciones sobre la imprudencia profesional, inhabilitación profesional y el trabajo en equipo», 173; Mirentxu Corcoy Bidasolo, El Delito imprudente. Criterios de imputación del resultado (Barcelona: PPU, 1989), 327; Jorge Barreiro, La imprudencia punible en la actividad médico-quirúrgica, 117; Hava García, La imprudencia 
jurisprudencial, en tanto JESCHECK y WEIGEND lo entienden como "una regla complementaria de origen consuetudinario que rige el tráfico viario". ${ }^{38}$ En cualquier caso, su reconocimiento pretendía limitar el excesivo alcance del criterio de la previsibilidad, eximiendo a los conductores de la obligación de adaptar su comportamiento a las posibles o previsibles actuaciones incorrectas de los terceros en la vía. Antes de su admisión, debido a los riesgos de la circulación rodada, regía para los tribunales alemanes una especie de "principio de desconfianza» que extendía extraordinariamente el deber de cuidado -la responsabilidad por imprudencia- y hacía en extremo compleja e insoportable la conducción. En efecto, sobre la base de esa especie de deber de desconfianza los conductores de automóviles no sólo debían estar pendientes en todo momento de los obstáculos de la carretera, sino que además debían contar con las posibles conductas incorrectas de los participantes del tráfico. ${ }^{39}$

Algunos autores -v.gr., GÓMEZ RIVERO, FEIJOO SÁNCHEZ y MARAVER GÓMEZ- señalan que el primero en utilizar este principio en el ámbito automovilístico fue el alemán GÜLDE en el año 1938. No obstante, también se dice que ya desde 1930 EXNER había llamado la atención sobre los problemas que podía generar el reconocimiento de un deber general de contar con las conductas antirreglamentarias de los terceros. Entre otras razones, señaló que con dicha postura no sólo no se lograba una mayor seguridad, sino que además se ponían serios impedimentos al desarrollo del tráfico viario. Por tanto, frente al criterio de la desconfianza propuso reconocer que el conductor que cumpliera correctamente las normas de circulación podría contar con que los demás hicieran también lo mismo, salvo que otra cosa se desprendiera de las circunstancias del caso concreto. ${ }^{40}$

En general puede decirse que entre las circunstancias que suscitaron el reconocimiento del principio de confianza figura la aparición en la segunda mitad de los años veinte de las primeras normas de preferencia de paso; la promulgación, en 1934, de una nueva ordenanza del tráfico viario -la Reichsstraßenverkehrsordnung- que sienta las bases para la admisión de una comunidad de tráfico que se resumía en la idea de una comunidad de participantes responsables en la circulación vial en la que cada

médica, 78; Villacampa Estiarte, Responsabilidad penal del personal sanitario. Atribución de responsabilidad penal en tratamientos médicos efectuados por diversos profesionales, $140 \mathrm{~s}$; Claus Roxin, Derecho Penal Parte General. Fundamentos. La estructura de la teoría del delito, trad. Diego-Manuel Luzón Peña, Miguel Díaz y García Conlledo, y Javier De Vicente Remesal, 2.a ed, vol. I (España: Civitas, S. A., 1997), 1004; Rodríguez Vázquez, Responsabilidad penal en el ejercicio de actividades médico-sanitarias. Criterios para delimitar la responsabilidad en supuestos de intervención conjunta de los profesionales sanitarios, $217 \mathrm{~s}$.

38 Hans Heinrich Jescheck y Thomas Weigend, Tratado de Derecho Penal Parte General, trad. Miguel Olmedo Cardenete, 5a edición, renovada y ampliada (Granada: Colmares, 2002), 626.

39 Maraver Gómez, «El principio de confianza en el Derecho Penal. Un estudio sobre la aplicación del principio de autorresponsabilidad en la teoría de la imputación objetiva», 7.

40 Gómez Rivero, La responsabilidad penal del médico, 396; Feijoo Sánchez, «El principio de confianza como criterio normativo de imputación en el Derecho penal: fundamento y consecuencias dogmáticas», 74, n. 113; Maraver Gómez, «El principio de confianza en el Derecho Penal. Un estudio sobre la aplicación del principio de autorresponsabilidad en la teoría de la imputación objetiva», 9-11, 97 s., en esta última fuente también se puede ver un minucioso estudio detallado sobre el origen y evolución del principio de confianza en el ámbito del tráfico viario. 
uno debía poder contar con que los otros fuesen conscientes de sus deberes y se comportasen conforme a los mismos. También tuvieron el cometido de contribuir a perfilar la definitiva configuración del principio de confianza las críticas y objeciones que en el plano doctrinal empezaron a realizar algunos autores -v.gr., GÜLDE y MÜLLER- a las tesis jurisprudenciales basadas en la desconfianza y la aparición de las primeras sentencias ${ }^{41}$ del Reichsgericht (Tribunal Supremo del Reich) que limitaban el deber de los conductores de contar con las posibles conductas incorrectas de los terceros. ${ }^{42}$

Con fecha 29 de enero de 1938 tuvo lugar la primera sentencia en la que se reconoce como principio general la posibilidad de contar con el correcto comportamiento de los terceros y la primera también en la que se utiliza la expresión «confiar». En ella se expresa que el principio según el cual, en el tráfico viario, debía contarse con los errores o descuidos de otros participantes no valía con carácter general -como se venía asumiendo- sino sólo bajo circunstancias especiales. De no darse esas circunstancias especiales, el conductor podía «confiar» en que los demás participantes se comportarían también conforme a las reglas del tráfico. En efecto, estas sentencias conducirían a que el Bundesgerichtshof (Tribunal Supremo Federal alemán) proclamara abiertamente, en 1955, la vigencia de un principio de confianza en el Derecho de la circulación vial que luego se encargó de ir consolidando. ${ }^{43}$

Como señala ROXIN, este principio, "en su forma más general afirma que quien se comporta debidamente en la circulación puede confiar en que otros también lo hagan, siempre y cuando no existan indicios concretos para suponer lo contrario". ${ }^{44}$ Así para su comprensión, mediante un sencillo ejemplo ilustra que a la luz de este postulado quien "tiene prioridad de paso en los cruces no precisa reducir su velocidad en atención a posibles infracciones de tráfico de otros conductores, sino que por regla general puede partir de la base de que se respetará su preferencia de paso. Si ello no sucede y se produce una colisión, únicamente existe imprudencia en quien desatendió la preferencia de paso". ${ }^{45}$

Hacia la década del sesenta se revela un pleno reconocimiento del principio de confianza en el tráfico viario como criterio para delimitar el deber de cuidado de los sujetos que intervenían en él. Así, en

41 Cfr. Sentencias del Tribunal Supremo del Reich de: 16 de septiembre de 1935, 9 de diciembre de 1935, 15 de septiembre de 1936, citadas en: Maraver Gómez, «El principio de confianza en el Derecho Penal. Un estudio sobre la aplicación del principio de autorresponsabilidad en la teoría de la imputación objetiva», 15-17.

42 Ibid., 8-22.

43 Ibid., 17-22.

44 Roxin, Derecho Penal Parte General. Fundamentos. La estructura de la teoría del delito, I:1004. En este sentido también: Maraver Gómez, «El principio de confianza en el Derecho Penal. Un estudio sobre la aplicación del principio de autorresponsabilidad en la teoría de la imputación objetiva», 41, $91 \mathrm{~s}$; Rodríguez Vázquez, Responsabilidad penal en el ejercicio de actividades médico-sanitarias. Criterios para delimitar la responsabilidad en supuestos de intervención conjunta de los profesionales sanitarios, 217 s; Diego-Manuel Luzón Peña, Curso de Derecho Penal Parte General, 3ra reimpresión, vol. I (Madrid: Editorial Universitas, S.A., 2004), 504; Jescheck y Weigend, Tratado de Derecho Penal Parte General, 626; De Vicente Remesal y Rodríguez Vázquez, «El médico ante el Derecho penal: consideraciones sobre la imprudencia profesional, inhabilitación profesional y el trabajo en equipo», 173.

45 Roxin, Derecho Penal Parte General. Fundamentos. La estructura de la teoría del delito, I:1004. 
la misma medida en que se fue consolidando en este ámbito empezó a plantearse, tanto por la doctrina como por la jurisprudencia, la posibilidad de su extensión a otros contextos en los que la producción del resultado típicamente desaprobado suele verse igualmente relacionado con la intervención de varias personas. Sobre esta base se proyectó su aplicación a la actividad médica, en las relaciones de empresa, en la responsabilidad por el producto, en la construcción y asociado a los accidentes laborales, experimentando una progresiva extensión hasta convertirlo en un instrumento dogmático de carácter general con el cual determinar el deber de cuidado dentro de la estructura del delito imprudente tradicionalmente pensado para conductas individuales. ${ }^{46}$

MAURACH, GÖSSEL y ZIPF, figuran entre los autores alemanes que afirman que "el principio de confianza debe ser extendido a los demás casos de la participación social conjunta”. ${ }^{47}$ Asimismo, en Latinoamérica ZAFFARONI, ALAGIA y SLOKAR se muestran a favor de la extensión de este principio a otros sectores de actividad distintos a los del tránsito. ${ }^{48}$ En cambio, como señalan GÓMEZ MARAVER y RODRÍGUEZ VÁZQUEZ, ciertos autores se mostraron escépticos e incluso algunos rechazan dicha extensión. La diferencia que se produce entre actividades con intervinientes anónimos como lo es la del tráfico viario y la especial vinculación entre los sujetos que tiene lugar en los supuestos de división del trabajo en los que existe una relación profesional (vertical u horizontal) y de conocimiento previo entre los intervinientes, como ocurre en la actividad médica y empresarial, son algunas de las razones que suelen aducirse. ${ }^{49}$

En este debate ROXIN señala que "aún está poco claro hasta qué punto puede extenderse el principio de confianza a otros ámbitos o sectores de la vida”. Sin embargo, con ello no quiso sostener una

46 Cfr. Gómez Rivero, La responsabilidad penal del médico, 396; Maraver Gómez, «El principio de confianza en el Derecho Penal. Un estudio sobre la aplicación del principio de autorresponsabilidad en la teoría de la imputación objetiva», 96 ss; Rodríguez Vázquez, Responsabilidad penal en el ejercicio de actividades médico-sanitarias. Criterios para delimitar la responsabilidad en supuestos de intervención conjunta de los profesionales sanitarios, $218 \mathrm{ss.}$

47 Reinhart Maurach, Karl Heinz Gössel, y Heinz Zipf, Derecho penal Parte general. Formas de aparición del delito y las consecuencias jurídicas del hecho, trad. Jorge Bonfill Genzsch, 7a edición, vol. 2 (Buenos Aires: Editorial Astrea, 1995), 159.

48 Eugenio Raúl Zaffaroni, Alejandro Alagia, y Alejandro Slokar, Derecho Penal: parte general, 2a edición (Buenos Aires, Argentina: Ediar Sociedad Anónima Editora, Comercial, Industrial y Financiera, 2002), 559 s. «Frecuentemente se plantean problemas complejos en materia de imprudencia cuando se trata de acciones que forman parte de una actividad compartida, como puede ser una intervención quirúrgica o el tránsito. Toda vez que se trata de actividades en las que rige una división del trabajo o de la tarea, el criterio que se aplica para determinar la medida de la creación de un peligro prohibido es, en estos casos, el principio de confianza, según el cual no viola el deber de cuidado la acción del que confía en que el otro se comportará correctamente, mientras no tenga razón suficiente para dudar o creer lo contrario».

49 Maraver Gómez, «El principio de confianza en el Derecho Penal. Un estudio sobre la aplicación del principio de autorresponsabilidad en la teoría de la imputación objetiva», 124; Rodríguez Vázquez, Responsabilidad penal en el ejercicio de actividades médico-sanitarias. Criterios para delimitar la responsabilidad en supuestos de intervención conjunta de los profesionales sanitarios, 221. Sobre las diferencias existentes entre el ámbito médico y el automovilístico, Villacampa Estiarte, Responsabilidad penal del personal sanitario. Atribución de responsabilidad penal en tratamientos médicos efectuados por diversos profesionales, 142. 
oposición a las posibilidades de su aplicación a otros sectores de actividad diferentes del tránsito. Su preocupación parece radicar más bien en cuanto al alcance que este ha de tener en dichos ámbitos según las particularidades que se producen en ellos. Así no los hace aseverar el hecho de que seguidamente manifiesta que "se reconoce en principio su extensión al caso de la cooperación con división del trabajo, sobre todo en el ámbito de la actuación médica (v.gr. en un equipo de operaciones)" ${ }^{50}$

En efecto, en cuanto a la aplicación del principio de confianza al ámbito médico que aquí interesa, existe acuerdo en afirmar que también en ello la doctrina penal también fue pionera. ${ }^{51}$ Se dice que fue SCHMIDT uno de los primeros autores en preguntarse si la responsabilidad por imprudencia del médico debía abarcar los errores que cometen las personas con las cuales comparte la asistencia médica al paciente. A su juicio, esta posibilidad debe ser descartada en tanto que el propio hecho de recurrir a la colaboración de un tercero para llevar a cabo un acto médico no se considere en sí mismo desaprobado. Por tanto, para este autor, también en este sector de actividad que presenta la actuación conjunta de varias personas, el médico ha de tener la posibilidad de «confiar» en que el tercero cumplirá su deber, siempre y cuando esa confianza no pueda ser cuestionada. ${ }^{52}$

También ENGISHC, al estudiar la responsabilidad penal del cirujano por los errores cometidos por la enfermera, estableció un paralelismo con los casos en los que el conductor causa un accidente por la actuación incorrecta de un tercero o de la propia víctima. Luego, concluyó que la determinación de la responsabilidad penal del médico ante las conductas incorrectas de sus colaboradores no puede resolverse sin tener en cuenta la división del trabajo que se produce necesariamente en el ámbito de la medicina. Esa división del trabajo conlleva no sólo que el médico pueda contar con la ayuda de otras personas, sino también que pueda tener cierta confianza en la conducta correcta de esas otras personas de modo que la división del trabajo fuese funcional. En síntesis, para este autor, el principio de confianza desarrollado por la jurisprudencia en el ámbito del tráfico viario debía ser aplicado, junto con sus propias limitaciones, a todos los casos en los que se produce una división del trabajo. ${ }^{53}$

También STRATENWERTH, poco después del reconocimiento del principio de confianza en el tráfico viario por la jurisprudencia alemana, defendió su utilización para determinar la responsabilidad penal del médico. En este sentido sostiene que los tradicionales criterios basados en la previsibilidad y en la evitabilidad son insuficientes para concretar el deber de cuidado y determinar la responsabilidad por imprudencia en este caso porque están pensados para un modelo de actuación individual que no

50 Roxin, Derecho Penal Parte General. Fundamentos. La estructura de la teoría del delito, I:1005

51 Rodríguez Vázquez, Responsabilidad penal en el ejercicio de actividades médico-sanitarias. Criterios para delimitar la responsabilidad en supuestos de intervención conjunta de los profesionales sanitarios, 219 n. 76.

52 Maraver Gómez, «El principio de confianza en el Derecho Penal. Un estudio sobre la aplicación del principio de autorresponsabilidad en la teoría de la imputación objetiva», 98 s; Gómez Rivero, La responsabilidad penal del médico, 396. 53 Maraver Gómez, «El principio de confianza en el Derecho Penal. Un estudio sobre la aplicación del principio de autorresponsabilidad en la teoría de la imputación objetiva», 99 s. 
se corresponde con la división del trabajo que se ha terminado imponiendo en la actividad médica. A su juicio, en este contexto existe un ámbito de responsabilidad primario basado en una relación directa con el hecho y un ámbito de responsabilidad secundaria o derivada basada en una relación con el hecho mediado por la actuación responsable de un tercero. En consecuencia, el sujeto que confía en que el tercero actuará cumpliendo con su deber de cuidado sólo puede ser penalmente responsable si incumple deberes de cuidado de carácter secundario. ${ }^{54}$

A pesar de la controversia que ha existido en torno a la extensión del principio de confianza desde el tránsito a otros sectores de actividad, lo cierto es que hoy casi nadie se cuestiona, ni en la doctrina ni en la jurisprudencia, ${ }^{55}$ la importancia de su aplicación en la praxis médica. Es incuestionable que en este ámbito constituye un como instrumento válido para determinar el alcance de la responsabilidad penal del médico y del resto de las personas que con él participan en la asistencia sucesiva o simultánea a un paciente aunque con base en la división del trabajo. En la actualidad, esta es la tesis mayoritaria y sólo se apartan de ella aquellos autores que son contrarios a la asunción de este principio como herramienta dogmática a utilizar para definir el ámbito del cuidado debido en cualquier contexto que suponga la intervención de varios sujetos en la relación de una actividad. No obstante, algunos autores se han ocupado de destacar las particularidades que se producen en cada sector para rechazar una trasposición automática del principio de confianza desarrollado en el ámbito del tránsito en el que las reglas de cuidado contienen los resultados de la larga experiencia en la lucha contra los riesgos derivados de esta actividad. Esto no significa que tenga en este ámbito una naturaleza distinta, pues son diferencias o matices que simplemente condicionan un mayor o menor alcance de este principio en función de los presupuestos que le son propios. ${ }^{56}$

\section{FUNDAMENTO, PRESUPUESTOS Y LÍMITES DEL PRINCIPIO DE CONFIANZA EN LA PRAXIS MÉDICA}

En la medicina actual, desarrollada en las condiciones propias de la división del trabajo, el alcance del principio de confianza será diferente según nos encontremos ante una relación horizontal o vertical entre los distintos profesionales de la salud que intervienen en la asistencia al paciente. Es por ello que cuando se habla de la delimitación de responsabilidades en actuaciones conjuntas con resultados infaustos, un primer filtro lo constituye el principio de división del trabajo. El mismo ofrece-como se expuso

\footnotetext{
54 Ibid., 100-101.
}

55 Una referencia a varias sentencias en las que se reconoce el principio de confianza en Alemania y en España se puede ver en: Ibid., 102-4; Rodríguez Vázquez, Responsabilidad penal en el ejercicio de actividades médico-sanitarias. Criterios para delimitar la responsabilidad en supuestos de intervención conjunta de los profesionales sanitarios, $220 \mathrm{n}$. $78 \mathrm{~s}$.

56 Rodríguez Vázquez, Responsabilidad penal en el ejercicio de actividades médico-sanitarias. Criterios para delimitar la responsabilidad en supuestos de intervención conjunta de los profesionales sanitarios, $221 \mathrm{~s}$; Maraver Gómez, «El principio de confianza en el Derecho Penal. Un estudio sobre la aplicación del principio de autorresponsabilidad en la teoría de la imputación objetiva», 102-5; Villacampa Estiarte, Responsabilidad penal del personal sanitario. Atribución de responsabilidad penal en tratamientos médicos efectuados por diversos profesionales, 142. 
supra- las primeras pautas sobre las competencias y/o alcance del ámbito de cuidado que corresponde a cada uno de los intervinientes en la actividad común. Una vez determinado este en relación con la actividad común aún habrá que evaluar los márgenes de aplicación del principio de confianza respecto a la actuación de los terceros que con el interactúan. Sólo la conjugación de ambos criterios viabilizará la respuesta a la siguiente interrogante: jen los casos de lesiones o muertes producidas a partir de una actividad médica realizada en régimen de división del trabajo, se podrá exigir algún responsabilidad penal además de a quien realizaba directamente la conducta imprudente, a los otros sujetos que con él interactuaban?

Según la doctrina, en su forma más general el principio de confianza postula que quien se comporta debidamente en el contexto de una actividad conjunta puede confiar en que los demás también lo hagan, siempre y cuando no existan indicios concretos para suponer lo contrario. ${ }^{57}$ De este modo se fija un límite y establece hasta dónde tiene que llegar el cuidado de cada uno de los que forman parte de una actividad compartida en relación a la conducta del tercero con el cual interactúa. Tal vez por ello STRATENWERTH, exprese que este principio se fundamenta en la responsabilidad de los terceros y en la posibilidad de diferenciar un ámbito de responsabilidad primario basado en una relación directa con el hecho y un ámbito de responsabilidad secundario basado en una relación con el hecho, mediada por la actuación responsable de un tercero. ${ }^{58}$

No obstante, existe cierto acuerdo sobre las razones que con carácter general fundamentan la validez del principio de confianza. En ese sentido se argumenta que si en el contexto de una actividad compartida se estuviera obligado a supervisar en todos los casos las conductas de los colaboradores, la división del trabajo sería completamente apócrifa. Obligar a un sujeto a valorar las conductas de los otros que con el interactúan como parte del riesgo asumido a través de su propia actuación, supondría dejar sin efecto el principio de división del trabajo y todas las ventajas que de él se derivan. En el ejercicio de la medicina, v.gr., los sujetos no podrían concentrarse suficientemente en su trabajo que se vería sobrecargado por la exasperación de los deberes de diligencia, incluso, algunos colaboradores sabiéndose controlados, podrían reducir el nivel de atención. ${ }^{59}$

57 Gómez Rivero, La responsabilidad penal del médico, 395; Vallejo Jiménez, «Responsabilidad penal sanitaria: problemas específicos en torno a la imprudencia médica», 163; Roxin, Derecho Penal Parte General. Fundamentos. La estructura de la teoría del delito, I:1004; Rodríguez Vázquez, Responsabilidad penal en el ejercicio de actividades médico-sanitarias. Criterios para delimitar la responsabilidad en supuestos de intervención conjunta de los profesionales sanitarios, 216; Bernate Ochoa, Imputación objetiva y responsabilidad penal médica, 162; Lombana Villalba, Derecho Penal y responsabilidad médica, 266; Zaffaroni, Alagia, y Slokar, Derecho Penal: parte general, 559 s; Nilson Poveda Buitrago, Imputación objetiva, acciones a propio riesgo y responsabilidad penal médica en Colombia (Bogotá: Grupo Editorial Ibáñez, 2014), 104,105,167,168,175-179; Andrea Perín, «Imprudencia penal médica. Definición criteriológica de un modelo de imputación deóntico y liberal», en Derecho y medicina defensiva: legitimidad y límites de la intervención penal (Bilbao-Granada: Editorial Comares, S.L, 2020), 136.

58 Citado en: Maraver Gómez, «El principio de confianza en el Derecho Penal. Un estudio sobre la aplicación del principio de autorresponsabilidad en la teoría de la imputación objetiva», 100-101.

59 Gómez Rivero, La responsabilidad penal del médico, 402; Maraver Gómez, «El principio de confianza en el Derecho 
Además, tal como señala GÓMEZ RIVERO, el principio de confianza, respetuoso de la realidad fenomenológica de la praxis médica, ofrece:

[...] un punto de equilibrio entre los dos intereses contrapuestos que están en la base de la responsabilidad del trabajo en equipo: por un lado, evitar que la misma, bien se diluya en una disputa cruzada sobre los ámbitos de competencia, bien se focalice sobre el concreto ejecutor ignorando las coordenadas más amplias propias de la red de interrelaciones que genera la división de tareas; por otro, respetar la exigencia de no vaciar de contenido el sentido mismo del reparto de funciones, que no es otro que permitir la especialización, garantizando que cada uno de los participantes se centre en el respectivo ámbito que tiene encomendado. ${ }^{60}$

También la opinión existe cierta unanimidad en la ubicación sistemática de este principio en el tipo de injusto asociado a la teoría del delito imprudente. No obstante, algunos autores consideran que como criterio delimitador del riesgo no permitido se integra en la imputación objetiva. Conforme a esta forma de pensar es clara su ubicación en la parte objetiva del tipo penal. Para otros, como criterio delimitador del deber de cuidado quedaría ubicado allí donde se analice tal deber según la concepción que se adopte asociada a la teoría del delito. En efecto, la ubicación sistemática del principio de confianza como criterio de determinación del deber de cuidado depende de la construcción dogmática de la imprudencia que tenga cada autor. Con independencia de lo anterior su contenido es válido en el seno de cualquier sistemática de la teoría jurídica del delito, aunque cuanto antes se tenga en cuenta en la estructura de la infracción penal más importante serán sus efectos jurídicos-penales. Asimismo, la función que desempeña este principio es básicamente la misma se defina como criterio delimitador del deber de cuidado o de exclusión de la imputación objetiva. En cualquiera de estos casos se trata de un principio restrictivo del tipo. ${ }^{61}$

En consecuencia, a la hora de definir la base dogmática sobre la cual se erige este principio, la doctrina mayoritaria lo cimenta en el riesgo permitido, mientras otro sector no despreciable, lo hace en el

Penal. Un estudio sobre la aplicación del principio de autorresponsabilidad en la teoría de la imputación objetiva», 100; Rodríguez Vázquez, Responsabilidad penal en el ejercicio de actividades médico-sanitarias. Criterios para delimitar la responsabilidad en supuestos de intervención conjunta de los profesionales sanitarios, 304; Vallejo Jiménez, «Responsabilidad penal sanitaria: problemas específicos en torno a la imprudencia médica», 165.

60 Gómez Rivero, La responsabilidad penal del médico, 402. También destacan el valor dogmático del principio de confianza como herramienta que viene a superar las insuficiencias de un esquema clásico del delito imprudente pensado sólo para conductas individuales, entre otros: Vallejo Jiménez, «Responsabilidad penal sanitaria: problemas específicos en torno a la imprudencia médica», 163; Zaffaroni, Alagia, y Slokar, Derecho Penal: parte general, 559; Rodríguez Vázquez, Responsabilidad penal en el ejercicio de actividades médico-sanitarias. Criterios para delimitar la responsabilidad en supuestos de intervención conjunta de los profesionales sanitarios, 222.

61 Feijoo Sánchez, «El principio de confianza como criterio normativo de imputación en el Derecho penal: fundamento y consecuencias dogmáticas», 71 s; Rodríguez Vázquez, Responsabilidad penal en el ejercicio de actividades médico-sanitarias. Criterios para delimitar la responsabilidad en supuestos de intervención conjunta de los profesionales sanitarios, 222-37. 
principio de autorresponsabilidad, ${ }^{62}$ pero existen posturas intermedias ${ }^{63}$ que pueden ser reconducidas a una de las dos posiciones principales. ${ }^{64}$ Conforme a la institución del riesgo permitido, se considera que las acciones de aquellos con quienes se interactúa constituyen riesgos o peligros que, hasta cierto punto, pueden ser asumidos. Sólo si las conductas de los terceros superan ciertas barreras, aumentando el riesgo inicial que llevan aparejadas, perderá eficacia el principio de confianza y aparecerá la obligación secundaria de adecuar su conducta a la de aquel otro, con la finalidad de evitar el resultado lesivo. Desde los postulados del principio de autorresponsabilidad, la confianza en el otro está permitida porque cada sujeto como ser libre y autónomo es responsable de los resultados derivados de su actuación. Al igual que el otro puede esperar de mí un comportamiento correcto yo debo esperar del otro lo mismo, siendo ello motivo suficiente para confiar en que va a actuar correctamente y por lo menos inicialmente "ningún sujeto tiene que ser policía del otro". ${ }^{65}$

La crítica que los defensores de cada línea formulan a la otra nos conduce a pensar que aquellos esfuerzos devenidos en posturas intermedias se encuentran justificados. Cada una de estas teorías por sí sola resulta insuficiente como cimiento dogmático para el entendimiento del principio de confianza, su aplicación y los diferentes límites a su eficacia. Que el sujeto sea responsable de sus propios actos no significa que su conducta vaya a ser correcta, es decir, existe un riesgo cuya amplitud habrá que concretar. Asimismo, afirmar que una persona es factor de riesgo supone plantear desde el principio un obstáculo que haría difícil sino imposible la actividad en conjunto con otros sujetos. También se sostiene que las acciones de terceras personas no pueden ser concebidas por el ordenamiento jurídico, al menos como punto de partida de su valoración, como un riesgo más a tener en cuenta por quienes con ellos interactúan. Adoptar este punto de partida supondría hacer equivaler los riesgos procedentes de sucesos naturales a los peligros generados por comportamientos humanos. En conclusión, asumimos la postura intermedia según la cual el principio de confianza se basa en el riesgo permitido y en el principio de autorresponsabilidad. ${ }^{66}$

Inicialmente la eficacia del principio de confianza opera bajo los cánones del principio de autorresponsabilidad pero si las conductas de los terceros superan ciertas barreras, aumentando el riesgo inicial que llevan aparejadas, entonces bajo los preceptos del riesgo permitido perderá eficacia el principio de

62 Poveda Buitrago, Imputación objetiva, acciones a propio riesgo y responsabilidad penal médica en Colombia, 105.

63 Entre ellas, tenemos una posición mixta defendida por la alemana Peter resultado de la combinación de las líneas principales. También destaca Maurach al defender la relación del principio de confianza con la adecuación social; Tamarit Sumalia con su construcción de la teoría de los ámbitos o esferas de responsabilidad y Jakobs que lo concibe como raíz de la prohibición de regreso. Vid. Rodríguez Vázquez, Responsabilidad penal en el ejercicio de actividades médico-sanitarias. Criterios para delimitar la responsabilidad en supuestos de intervención conjunta de los profesionales sanitarios, 224-37.

64 Cfr. Ibid., 235.

65 Ibid., 236.

66 Ibid. 
confianza. En este momento aparecerá la obligación secundaria de adecuar la conducta a la de aquel otro y se amplía el alcance del deber de cuidado con la finalidad de evitar el resultado lesivo. Si se asumiera únicamente el principio de autorresponsabilidad, aun en los supuestos de indicios o evidencias del comportamiento imprudente del otro, el sujeto que con él participa en una misma actividad no tendría por qué modificar su conducta para ampliar su deber de cuidado; en definitiva, cada uno es responsable de sus propias actuaciones.

Ahora bien, con independencia de la opción dogmática que se asuma sobre la base dogmática del principio de confianza, existe un acuerdo prácticamente unánime en la doctrina en relación a las denominadas excepciones, límites o restricciones que le son propias. ${ }^{67}$ Estos son el resultado de un conjunto de circunstancias, supuestos o requisitos que han de concurrir para que pueda configurarse y esgrimirse en un caso concreto. Si bien este principio postula que cada participante en una actividad compartida puede y tiene que confiar en que la actuación del resto de los intervinientes será correcta, es comprensible que ello no deba ser entendido de una manera absoluta. La literatura científica revela diferentes aproximaciones en esta dirección tanto en sentido general como enmarcado en el ámbito médico.

De un modo particularmente notable destaca, entre las diversas fuentes, la sistematización realizada por MARAVER GÓMEZ, ${ }^{68}$ quien señala que para la apreciación del principio de confianza resulta indispensable la evaluación de dos requisitos que limitan la posibilidad de su aplicación. Primero: que el sujeto sólo puede confiar si ha actuado correctamente y, segundo: que no existan circunstancias en el caso concreto que evidencien que el tercero se va a comportar incorrectamente.

Sólo puede confiar si ha actuado correctamente. Conforme a esta primera exigencia, la aplicación del principio de confianza sólo se realizará a favor de aquel que haya obrado cuidadosamente en su propio ámbito de actuación. Quien infringe su deber de cuidado más inmediato no puede, amparándose en este principio, esperar que los otros realicen con corrección la concreta función que les corresponde y que además subsanen el peligro que deriva de su comportamiento.

Sin embargo, la sola determinación del actuar incorrecto no es razón suficiente para la limitación automática a la posibilidad de confiar. Para hacer responsable a un sujeto de un resultado lesivo en el

67 Corcoy Bidasolo, El Delito imprudente. Criterios de imputación del resultado, 88; Jorge Barreiro, La imprudencia punible en la actividad médico-quirúrgica, 118 y ss; Choclán Montalvo, Deber de cuidado y delito imprudente, 112 y ss; Feijoo Sánchez, «El principio de confianza como criterio normativo de imputación en el Derecho penal: fundamento y consecuencias dogmáticas», 116 y ss; Hava García, La imprudencia médica, 78 y ss; Villacampa Estiarte, Responsabilidad penal del personal sanitario. Atribución de responsabilidad penal en tratamientos médicos efectuados por diversos profesionales, 147 y ss; Gómez Rivero, La responsabilidad penal del médico, 395; Rodríguez Vázquez, Responsabilidad penal en el ejercicio de actividades médico-sanitarias. Criterios para delimitar la responsabilidad en supuestos de intervención conjunta de los profesionales sanitarios, 237 y ss. En la doctrina alemana: Kirschbaum, Wilhelm, Schumann, Krumpelmann, Bockelmann y Volk, Cramer y Sterberg-Liben, referenciados por: Ibid., 238, n. 125.

68 Maraver Gómez, «El principio de confianza en el Derecho Penal. Un estudio sobre la aplicación del principio de autorresponsabilidad en la teoría de la imputación objetiva», 125-59. 
contexto de una actividad conjunta, no basta que haya infringido un deber de cuidado. Sólo si el error del tercero ha sido derivado de dicha infracción entonces puede que tenga que responder penalmente también del resultado infausto, no pudiéndose amparar en la confianza de que el tercero obraría correctamente. ${ }^{69}$ Hacerlo responder siempre por la mera infracción de su deber de cuidado supondría una sanción inadmisible de un versari in re illicita ${ }^{70}$ por ello la importancia de trazar límites al alcance de este presupuesto de aplicación, exigiendo una relación entre la infracción del sujeto y la conducta incorrecta del tercero. Como ha advertido ROXIN, existen determinados supuestos en que aun habiendo actuado incorrectamente se puede seguir invocando el principio de confianza, en concreto, cuando la infracción no haya repercutido en el resultado lesivo. ${ }^{71}$

Solo se podrá confiar si no existen circunstancias en el caso concreto que evidencien que el tercero se va a comportar incorrectamente. La exigencia de este requisito para la apreciación del principio de confianza constituye su limitación más antigua, comúnmente aceptada en el presente por los países que más lo han desarrollado (Alemania y España). ${ }^{72}$ Bajo esta consideración la posibilidad de confiar queda excluida siempre que en el caso concreto resulte "claramente previsible» que el tercero se va a

69 No obstante, no se deben confundir en este análisis cuestiones relativas a la relación de causalidad o la imputación objetiva, distintas de la eficacia y amplitud del principio de confianza. Vid. Corcoy Bidasolo, El Delito imprudente. Criterios de imputación del resultado, 330; Choclán Montalvo, Deber de cuidado y delito imprudente, 116; Feijoo Sánchez, «El principio de confianza como criterio normativo de imputación en el Derecho penal: fundamento y consecuencias dogmáticas», 118; Rodríguez Vázquez, Responsabilidad penal en el ejercicio de actividades médico-sanitarias. Criterios para delimitar la responsabilidad en supuestos de intervención conjunta de los profesionales sanitarios, 240-41.

70 Así lo han manifestado, Corcoy Bidasolo, El Delito imprudente. Criterios de imputación del resultado, 330; Roxin, Derecho Penal Parte General. Fundamentos. La estructura de la teoría del delito, I:1005; Feijoo Sánchez, «El principio de confianza como criterio normativo de imputación en el Derecho penal: fundamento y consecuencias dogmáticas», 118; Maraver Gómez, «El principio de confianza en el Derecho Penal. Un estudio sobre la aplicación del principio de autorresponsabilidad en la teoría de la imputación objetiva», 128-29.

71 Roxin, Derecho Penal Parte General. Fundamentos. La estructura de la teoría del delito, I:1005. Este autor a través de un ejemplo del tráfico rodado señala: «Por tanto, quien conduce un coche en un estado de incapacidad para conducir a consecuencia del consumo de alcohol, a pesar de ello debe quedar exento de responsabilidad penal invocando el principio de confianza cuando otro no respeta su prioridad de paso y el accidente tampoco habría sido evitable para el conductor sobrio. El "castigo" del conductor alcoholizado con la pérdida del derecho a la protección de la confianza supondría la sanción inadmisible de un versari in re illicita. En cambio, quien ha puesto en peligro con su conducta incorrecta a otros intervinientes en la circulación y ha contribuido de este modo a un accidente no puede en efecto invocar el principio de confianza»

72 Rodríguez Vázquez, Responsabilidad penal en el ejercicio de actividades médico-sanitarias. Criterios para delimitar la responsabilidad en supuestos de intervención conjunta de los profesionales sanitarios, 242; Roxin, Derecho Penal Parte General. Fundamentos. La estructura de la teoría del delito, I:1004; Choclán Montalvo, Deber de cuidado y delito imprudente, 113; Feijoo Sánchez, «El principio de confianza como criterio normativo de imputación en el Derecho penal: fundamento y consecuencias dogmáticas», 119; Hava García, La imprudencia médica, 79; Esther Hava García, La imprudencia inconsciente (Granada: Comares, 2002), 162; Zaffaroni, Alagia, y Slokar, Derecho Penal: parte general, 560; Villacampa Estiarte, Responsabilidad penal del personal sanitario. Atribución de responsabilidad penal en tratamientos médicos efectuados por diversos profesionales, 147; Gómez Rivero, La responsabilidad penal del médico, 395; Maraver Gómez, «El principio de confianza en el Derecho Penal. Un estudio sobre la aplicación del principio de autorresponsabilidad en la teoría de la imputación objetiva», 131 y ss. 
comportar incorrectamente. En esa dirección se precisan en la doctrina circunstancias que según el caso en concreto limitan la posibilidad de confiar, entre las que cuentan, según expone MARAVER GÓMEZ, "la particular condición del tercero, el tipo de situación o la frecuencia con la que se cometen ciertas infracciones" ${ }^{73}$ Son circunstancias que como referentes de valoración y sin llegar al casuismo sugieren motivos para pensar que el tercero se va a comportar incorrectamente.

Circunstancias relacionadas con la persona del tercero. ${ }^{74}$ Entendida como una verdadera excepción al principio de confianza respecto a terceros incapaces o inimputables, ha sido comúnmente aceptada y reconocida con carácter general. ${ }^{75}$ Sin embargo, no encuentra especial aplicación en el ámbito de actuación médica; porque es difícil imaginar que un profesional de la salud forme parte de un grupo o equipo médico cuando por sus condiciones personales fuese previsible su incapacidad para la participación en un acto potencialmente peligroso por naturaleza.

Circunstancias relacionadas con la situación concreta. Significa que hay situaciones en las que existen motivos concretos para pensar que el tercero se va a comportar incorrectamente, en cuyos supuestos no opera el principio de confianza. "Si el tercero se muestra, por ejemplo, ebrio, asustado, poco preparado, cansado o despistado, se entiende que puede haber suficientes motivos para esperar una conducta incorrecta y limitar, por tanto, la aplicación del principio de confianza”. ${ }^{76}$ También puede ser que se encuentre en condiciones de actuar correctamente, pero resulte evidente o especialmente previsible que va a realizar una conducta incorrecta. De igual modo, no se podrá argüir la protección de este principio cuando se observa que el tercero ha empezado a comportarse incorrectamente o ha realizado ya una conducta inadecuada. ${ }^{77}$

Circunstancias relacionadas con la infracción del tercero: las "infracciones típicas". Conforme a este criterio, un límite a la posibilidad de esgrimir el principio de confianza es la frecuencia con la que se

73 Maraver Gómez, «El principio de confianza en el Derecho Penal. Un estudio sobre la aplicación del principio de autorresponsabilidad en la teoría de la imputación objetiva», 113.

74 Ibid., 134. “(...) el Tribunal Supremo (alemán), en sus primeras sentencias sobre el principio de confianza, indicaba que la regla general establecida por este principio se limita «cuando el conductor respetuoso puede prever en otro usuario vial una posible conducta antirreglamentaria de peligro concreto, atendiendo a las circunstancias personales y externas»; o que, más concretamente, el principio de confianza "puede ceder en casos determinados, en que tratándose de niños, ancianos o minusválidos es previsible su reacción anormal»".

75 Roxin, Derecho Penal Parte General. Fundamentos. La estructura de la teoría del delito, I:1005; Rodríguez Vázquez, Responsabilidad penal en el ejercicio de actividades médico-sanitarias. Criterios para delimitar la responsabilidad en supuestos de intervención conjunta de los profesionales sanitarios, 247-49; Maraver Gómez, «El principio de confianza en el Derecho Penal. Un estudio sobre la aplicación del principio de autorresponsabilidad en la teoría de la imputación objetiva», 133-38; Feijoo Sánchez, «El principio de confianza como criterio normativo de imputación en el Derecho penal: fundamento y consecuencias dogmáticas», 123.

76 Maraver Gómez, «El principio de confianza en el Derecho Penal. Un estudio sobre la aplicación del principio de autorresponsabilidad en la teoría de la imputación objetiva», 139.

77 Ibid., 139-43. 
cometen determinadas infracciones. Según esta exigencia, "cuando la conducta incorrecta que cabe esperar del tercero forma parte de aquellas infracciones que se cometen tan a menudo que resulta difícil no contar con ellas, el sujeto no puede ampararse en el principio de confianza" ${ }^{78}$ Sin embargo, algunos autores rechazan que la frecuencia con la que se cometen determinadas infracciones sea motivo suficiente para negar la posibilidad de confiar. Para ello argumentan que son las reglas de la experiencia las que pueden fundamentar la confianza o no en la conducta correcta del tercero y sólo en última instancia pueden relacionarse con la periodicidad con la que se cometen ciertas conductas. ${ }^{79}$

De igual modo, expresión del grado de excepcionalidad en la apreciación del principio, también se adicionan otras limitaciones que se producen cuando existen determinados deberes de cuidado relacionados con la conducta de los terceros: deberes que consisten en prevenir o evitar la conducta incorrecta del tercero y deberes que pretenden compensar la posible conducta incorrecta del tercero. Ello implica que solo se pueda confiar si no existe un deber de evitar o compensar la conducta incorrecta del tercero. ${ }^{80} \mathrm{Su}$ estudio, como limitaciones a la posibilidad de confiar, ha cobrado auge en la medida en que se ha hecho extensiva la aplicación del principio a ámbitos como la medicina en los que se produce una división del trabajo con relaciones verticales y horizontales que le imprimen ciertas complejidades.

El deber de evitar la conducta incorrecta del tercero (relaciones de carácter vertical). Significa que cuando existe un deber de prevenir o evitar la conducta incorrecta del tercero por parte del sujeto actuante, la posibilidad que este tiene de confiar en aquel queda limitada desde el primer momento. Por regla general en la división del trabajo lo normal es que cada sujeto tengan definidos sus deberes en función del rol que desempeña. En el ámbito médico, v.gr., se reconoce la superior posición que ostentan algunos sujetos en su relación con el resto. Esa posición implica un mayor poder de decisión o dirección y a la vez genera ciertos deberes de cuidado (deberes de selección, instrucción, coordinación, vigilancia, control o supervisión) sobre la actuación de los subordinados. En tal caso, no se puede esperar a que haya motivos concretos que hagan pensar que el tercero se va comportar incorrectamente. Respecto a estos sujetos el principio de confianza opera con menor intensidad que en contextos en los que los sujetos mantienen una relación de carácter horizontal. ${ }^{81}$ No obstante, en aras de delimitar el alcance de esta restricción a la posibilidad de confiar, MARAVER GÓMEZ propone la clasificación en dos grupos de los deberes de estos sujetos con una posición jerárquica superior: deberes relacionados con la selección, la instrucción y la coordinación, y aquellos denominados de vigilancia, control o supervisión. ${ }^{82}$

78 Ibid., 144.

79 Ibid., 144-49.

80 Ibid., 125.

81 Ibid., 149-51; Rodríguez Vázquez, Responsabilidad penal en el ejercicio de actividades médico-sanitarias. Criterios para delimitar la responsabilidad en supuestos de intervención conjunta de los profesionales sanitarios, 249; Vallejo Jiménez, «Responsabilidad penal sanitaria: problemas específicos en torno a la imprudencia médica», 180-94.

82 Maraver Gómez, «El principio de confianza en el Derecho Penal. Un estudio sobre la aplicación del principio de autorresponsabilidad en la teoría de la imputación objetiva», 151. 
a) Deberes de selección, instrucción y coordinación

Conforme al deber de selección el sujeto que escoge a las personas que van a formar parte de una determinada actividad debe procurar que cuenten con la capacidad técnica y personal necesaria para realizar la tarea que les va a ser asignada. Si el sujeto no comprueba esa capacidad, no podrá apelar al principio de confianza y será responsable de los resultados lesivos ocasionados por los terceros (culpa in eligendo). ${ }^{83}$ Lo mismo ocurre, con sus peculiaridades en relación a los deberes de instrucción y coordinación. Según el primero, el sujeto que instruye a los terceros en el marco de una determinada actividad (bien puntualmente para una tarea concreta, bien con carácter general), debe realizar la instrucción acorde a los estándares exigidos y comprobar que el tercero haya recibido y comprendido correctamente las indicaciones.

Por otra parte, el deber de coordinación implica la obligación de establecer correctamente el reparto de tareas en función de las circunstancias materiales, temporales y personales presentes en cada caso. Ello para garantizar que la actividad resulte suficientemente segura y evitar, v.gr, que se produzcan conflictos de competencia (tanto de carácter positivo, cuando varias personas se consideran responsables de una misma tarea, como de carácter negativo, cuando una tarea queda sin tener asignada una persona responsable). ${ }^{84}$

b) Deberes de vigilancia, control o supervisión

Con estos deberes se limita la posibilidad de confiar porque al igual que ocurre con los de selección, instrucción y coordinación, el sujeto no puede esperar a que se presenten en el caso concreto circunstancias que hagan pensar que el tercero se va a comportar incorrectamente. A contrario sensu, se le exige el deber de comprobar la inexistencia de determinados aspectos que pueden dar lugar a la conducta incorrecta del tercero. La diferencia con aquellos radica en que estos suponen una mayor limitación de la posibilidad de confiar, pues se mantienen hasta el momento en el que el tercero realiza su conducta. No se trata aquí, como en aquellos casos, de garantizar las condiciones necesarias para establecer un reparto de tareas, sino de velar porque el tercero las realice correctamente. No obstante, el alcance de estos deberes puede ser distinto en función de que se exija, simplemente, examinar de manera constante las condiciones necesarias para que los terceros puedan cumplir con sus tareas o se requiera, además, comprobar la correcta ejecución de esas tareas. ${ }^{85}$

83 En la doctrina existen diversas opiniones de las restricciones al principio de confianza sobre la base de la competencia que se tenga para la efectiva selección de los integrantes del equipo médico. Incluso la limitación puede estar relación con el carácter público o privado del centro médico. Vid. Vallejo Jiménez, «Responsabilidad penal sanitaria: problemas específicos en torno a la imprudencia médica», 183-89.

84 Maraver Gómez, «El principio de confianza en el Derecho Penal. Un estudio sobre la aplicación del principio de autorresponsabilidad en la teoría de la imputación objetiva», 152.

85 Ibid., 153-54. 
Finalmente, el deber de compensar la posible conducta incorrecta del tercero: las "medidas de doble aseguramiento". Este supuesto se observa en el marco de la división horizontal del trabajo, en el que el deber de cuidado no deriva de la relación con una persona subordinada, sino de la necesidad de asegurar una determinada tarea. Bajo esa tesitura se sostiene que el deber del sujeto consiste en compensar los riesgos que pueda generar la conducta incorrecta del tercero como una suerte de doble aseguramiento que excluye por completo la posibilidad de confiar. ${ }^{86}$

Como se ha podido apreciar, en el marco de una actividad conjunta cada uno de los sujetos que intervienen tiene una responsabilidad directa o primaria en correspondencia con el rol que desempeńa y las acciones que realiza. Del mismo modo, también asume una responsabilidad secundaria, ${ }^{87}$ en relación a los errores con que obre el resto del equipo, siempre que incumpla deberes de cuidado de carácter secundario o derivado. Tales deberes surgen, cuando el riesgo ya ha aparecido como consecuencia de la conducta descuidada del tercero. Así, v.gr, cuando se aprecia una falta de atención o cualquier otra circunstancia que haga temer una conducta incorrecta por parte del tercero o cuando el propio sujeto provoca la conducta indebida de aquel..$^{88}$

En los supuestos de división horizontal del trabajo, identificados tradicionalmente en el ámbito médico con las relaciones que se establecen entre especialistas (v.gr. cirujano y anestesista) o entre el propio personal de enfermería, se considera que el principio de confianza despliega toda su eficacia. Sólo la perderá al desaparecer la situación de normalidad ante la concurrencia de circunstancias especiales que se deben concretar en una infracción del cuidado debido por parte del tercero. Se requiere que estas circunstancias resulten evidentes, se manifiesten intensamente y sean, por tanto, reconocible la infracción misma, la falta de cuidado del tercero que se manifiesta en una actuación claramente imprudente. En este supuesto de quiebra de la normalidad decae el principio de confianza y el sujeto que se encontraba amparado por este, debe ampliar su deber de cuidado hasta abarcar esa conducta imprudente. Si no lo hace también se podrá calificar como imprudente su conducta.

Frente al valor cuasi ilimitado del principio de confianza en la relación horizontal del trabajo, se establecen límites más estrictos en los supuestos de relación vertical. En aquellos casos de asistencia médica en la que intervienen, médicos y personal de enfermería, v.gr., o médicos especialistas y residentes, entre otros, se exige al superior el cumplimiento de una serie de deberes previos al acto de delegación para asegurar la validez del principio de confianza. En concreto y hasta donde sea posible, el superior jerárquico debe seleccionar correctamente al inferior al que encomienda una tarea y debe informarle e instruirle adecuadamente.

86 Ibid., 155-58.

87 Jesús-María Silva Sánchez, «Aspectos de la responsabilidad penal por imprudencia de médico anestesista. La perspectiva del Tribunal Supremo», DS 2 (diciembre de 1994): 42.

88 Maraver Gómez, «El principio de confianza en el Derecho Penal. Un estudio sobre la aplicación del principio de autorresponsabilidad en la teoría de la imputación objetiva», 100-101. 
En este sentido, la selección y la instrucción representa, en el caso de una división vertical del trabajo, los factores sobre los que se construye la confianza y las razones que justifican su ámbito de eficacia. Así, en caso de la producción de algún incidente del que pueda derivarse una responsabilidad penal, la persona que da las órdenes tiene de su lado el principio de confianza, siempre y cuando existan razones fundadas para pensar que el colaborador va a cumplir las órdenes. Se entiende que existen razones fundadas cuando el delegante ha realizado una correcta elección e instrucción de aquél si ha tenido la posibilidad de selección, no siempre potestad del superior jerárquico que desarrolla una actividad eventual con el tercero. No obstante, en determinados casos, el superior jerárquico ha de cumplir un deber de vigilancia y control sobre el inferior, con lo que el principio de confianza, verá reducido considerablemente su radio de acción.

\section{UNA MIRADA AL PRINCIPIO DE CONFIANZA EN CUBA DESDE LA LEY PENAL Y LA PRAXIS MÉDICA}

Una exploración de la Ley sustantiva penal cubana ${ }^{89}$ con el propósito de verificar la consagración del principio de confianza conduce a la conclusión de que no tiene en ella ancle jurídico-positivo. Tampoco se halla regulado en aquellas disposiciones jurídicas que integran el marco normativo asociado a la responsabilidad penal por mala praxis médica. ${ }^{90}$ En ninguna de ellas se hace referencia a este principio a pesar de su reconocida importancia por la doctrina foránea como herramienta dogmática para esclarecer la responsabilidad médica en el contexto del trabajo en equipo. Lo anterior no es motivo de preocupación si tenemos en cuenta que en Alemania, pionero en su concepción y desarrollo, tampoco tiene expresión normativa en su código punitivo. En el país germano -como se expuso supra- surgió como un principio de creación jurisprudencial que se fue consolidando doctrinalmente como instrumento con el cual limitar la responsabilidad por imprudencia en el ámbito del tráfico viario, generalizándose progresivamente su ámbito de aplicación a otros contextos de actuación conjunta en la que igualmente se produjeran resultados infaustos penalmente relevantes. En palabras de MARAVER GÓMEZ, aunque en el ordenamiento alemán se le intentó regular en la normativa de tráfico, a diferencia de lo que había terminado ocurriendo en otros ordenamientos, ${ }^{91}$ el principio de confianza no aparece expresamente

89 Cfr. Danilo Rivero García y María Caridad Bertot Yero, Código Penal de la República de Cuba Ley No. 62/87 (Anotado con las Disposiciones del CGTSP), 3a edición (La Habana: Ediciones ONBC, 2017).

90 Cfr. Cuba. Asamblea Nacional del Poder Popular, «Ley No. 41 "Ley de la Salud Pública”», 13 de julio de 1983, 41, http://www.parlamentocubano.gob.cu/index.php/documento/ley-de-la-salud-publica/; Cuba. Consejo de Ministros, «Decreto No. 139 "Reglamento de la Ley de Salud Pública”" (Gaceta Oficial Ordinaria No. 12, de fecha 22/02/1988, 4 de febrero de 1988), 41, http://juriscuba.com/wp-content/uploads/2015/10/Decreto-No.-139.pdf; República de Cuba. Ministerio de Salud Pública, «Resolución No. 458», 30 de noviembre de 2019, http://legislacion.sld.cu/index.php?P=FullRecord\&ID=156; Danilo Rivero García, Ley de Procedimiento Penal, Ley no. 5 de 13 de agosto de 1977 (Anotada y concordada con las Disposiciones del CGTSP), 2a edición (La Habana: Ediciones ONBC, 2012).

91 Maraver Gómez, «El principio de confianza en el Derecho Penal. Un estudio sobre la aplicación del principio de autorresponsabilidad en la teoría de la imputación objetiva», 38 n. 122. «En Austria, por ejemplo, se terminó reconociendo expresamente en el $\$ 3$ StVO de 1960: «Todo usuario de la vía pública puede confiar que las otras personas observen las normas jurídicas relativas a la utilización de la vía, salvo que reconozca que se trata de niños, ciegos, sordos, personas 
regulado. ${ }^{92}$ Tampoco en España -donde su reconocimiento se produjo algunos años más tarde producto de su importación desde Alemania- ${ }^{93}$ encuentra anclaje jurídico en su legislación sustantiva penal.

Sin embargo, a diferencia de lo que ocurre en Cuba, en ambos países resulta abundante -como se ha dejado ver en este trabajo- la producción bibliográfica y jurisprudencial en torno a este principio y también a su aplicación en el ámbito médico. En las publicaciones jurídicas de nuestro país sólo encontramos una ponencia presentada en el Congreso Internacional Abogacía 2012 por los abogados RAMÍREZ COLLEJO y BLANCO FONSECA, ${ }^{94}$ quienes toman como referencia esencial uno de los trabajos que sobre este tema desarrollara el profesor y abogado colombiano BERNATE OCHOA. ${ }^{95}$ Tampoco conocemos de ninguna sentencia de los Tribunales provinciales o del Tribunal Supremo Popular en la que se haga referencia al mismo. Esto denota que el principio de confianza ha estado prácticamente ausente del debate doctrinal y jurisprudencial en nuestro escenario lo que, como es natural, nos conduce a sostener que sobre este tópico aún no se predisponen pautas que faciliten la solución de los conflictos penales que pueden suscitarse asociado al trabajo en equipo, muy frecuente en la sociedad contemporánea.

En la búsqueda de otras fuentes que evidenciaran el reconocimiento del principio de confianza en el ámbito médico se examinaron los manuales de organización y procedimientos de algunas especialidades -Ortopedia y Traumatología, Cirugía y Ginecobstetricia- del "Hospital General Docente Dr. Agosthino Neto" de Guantánamo. Fue escogida la especialidad de cirugía por constituir el clásico ejemplo en el que actúa un equipo médico, tanto es así que la Resolución No. 1 de 2007 "Reglamento General de los Hospitales", se refiere al «equipo quirúrgico». ${ }^{96}$ No obstante, ni en esta ni en otras disposiciones del Ministerio de Salud Pública se clarifica lo que se debe entender por equipo médico como sí lo hace la legislación española. ${ }^{97}$ Las otras especialidades se seleccionaron para ilustrar que también en otras

con bastón blanco o brazalete amarillo, claramente impedidos o débiles o personas de cuya manifiesta actitud se deba deducir que son incapaces de valorar los peligros del tráfico y comportarse conforme a los mismos».

92 Ibid., 38-42.

93 Ibid., 7; Rodríguez Vázquez, Responsabilidad penal en el ejercicio de actividades médico-sanitarias. Criterios para delimitar la responsabilidad en supuestos de intervención conjunta de los profesionales sanitarios, 218.

94 Ramírez Collejo y Blanco Fonseca, «La exigencia de responsabilidad penal en la actividad médica bajo el principio de confianza».

95 Bernate Ochoa, «Responsabilidad penal médica, trabajo en equipo y principio de confianza».

96 Así lo hace en la SECCIÓN XI DEL PERSONAL MÉDICO DEL HOSPITAL. Artículo 73: Los médicos de asistencia o en función directa de la atención médica de los pacientes tendrán además de las obligaciones comunes a todos los trabajadores de una institución hospitalaria (Artículo 57) las siguientes: b) Los integrantes del equipo quirúrgico estarán en el salón de operaciones listos para comenzar las intervenciones a la hora señalada. Toda demora en el inicio de las intervenciones quirúrgicas exigen discusión y análisis por el jefe de servicio. (El subrayado es nuestro). Cfr. Cuba. Ministerio de Salud Pública, «Resolución Ministerial No. 1 "Reglamento General de Hospitales"», 9 de enero de 2007, https://files.sld.cu/minsapdocumentos/files/2009/08/reglamento-general-de-hospitales.pdf.

97 En el art. 9.2 de la Ley 44/2003 de 21 de noviembre -de ordenación de las profesiones sanitarias- en España se ha definido el concepto de equipo médico como "la unidad básica en la que se estructuran de forma uni o multiprofe- 
ramas de la Medicina existe trabajo en equipo con distribución de tareas específicas a sus miembros y la fáctica concreción de relaciones jerárquicas y horizontales.

El Manual de Organización y Procedimiento de la Unidad de Cirugía de este centro asistencial más que al equipo médico se refiere al conjunto de profesionales y trabajadores de la salud, médicos y paramédicos, que pertenecen a esta unidad. En esa dirección relaciona al jefe de sala, médicos cirujanos, médicos residentes, enfermera general, enfermeras, asistentes al paciente, secretaria, camilleros y pantristas. Como herramienta de gestión administrativa establece las funciones generales de cada uno, condiciones o requisitos que deben reunir y forma de contratación. Ciertamente, estos elementos revisten utilidad al momento de evaluar los límites del deber objetivo de cuidado, así como por las implicaciones que tienen en este contexto los deberes de selección, ${ }^{98}$ instrucción, coordinación, vigilancia, control o supervisión. Sin embargo, en ningún caso se explicitan las competencias y responsabilidades al momento de integrar un equipo médico ni el procedimiento para la selección del equipo quirúrgico.

El «Team Quirúrgico», como suelen denominarlo algunos médicos, está integrado como mínimo por el especialista en cirugía que lleva la jerarquía de la intervención quirúrgica, el anestesista y dos enfermeros (el circulante y el instrumentista). Generalmente el cirujano y el anestesista son acompañados de un médico residente de cada una de dichas especialidades. ${ }^{99}$ Ahora bien, no están reguladas o protocolizadas de forma exhaustiva las funciones, tareas y/o responsabilidades específicas de cada uno de los intervinientes. ${ }^{100}$ Estas son asumidas en razón de la costumbre que a veces se sustenta en los conocimientos adquiridos durante la formación o la propia praxis médica y que son trasmitidos de una generación a otra. Lo mismo ocurre en el resto de las mencionadas especialidades y sus respectivos manuales. Por otra parte, los criterios para la aplicación del principio de confianza en el ámbito médico tampoco son abordados en ninguna de las normas, manuales y protocolos consultados.

sional e interdisciplinar los profesionales y demás personal de las organizaciones asistenciales para realizar efectiva y eficientemente los servicios que les son requeridos". Cfr. «Ley 41/2002, de 14 de noviembre, básica reguladora de la autonomía del paciente y de derechos y obligaciones en materia de información y documentación clínica» («BOE» núm. 274 (BOE-A-2002-22188), 15 de noviembre de 2002), https://www.boe.es/buscar/pdf/2002/BOE-A-2002-22188-consolidado.pdf.

98 En entrevista con los médicos de la sala, estos explicaron que los integrantes del equipo quirúrgico son designados por los respectivos jefes de cada especialidad, léase: las enfermeras por el jefe de enfermería, el anestesista por el jefe de esta especialidad, etc.

99 Fuente: entrevista realizada el 24 de marzo de 2018 a cuatro especialistas en cirugía con un promedio de 26 años como especialistas y 30 de servicio.

100 La referencia que se hace en el Manual, entre otras, a las rutinas para la atención del paciente de cirugía (urgente y electiva) en el salón de operaciones es bien limitada. Así, por ejemplo: establece que la enfermera asistencial parapara al paciente con las indicaciones médicas y documentos para el salón de operaciones. La enfermera de preoperatorio lo recibe prepara para la intervención. El anestesista procede a anestesiar al paciente. El instrumentista, prepara el material quirúrgico a utilizar. El especialista y residente (en cirugía), realizan la intervención quirúrgica. De manera tal que no obran las funciones de los que intervienen, sino lo esencial o global de lo que se debe hacer. 
En resumen, resultado del análisis documental se advierte la existencia de manuales de organización con un incipiente nivel de regulación de las actividades de los profesionales y auxiliares de la salud en las diferentes salas. Por tanto, aunque no existe una norma específica que defina lo que debe entenderse por equipo médico, estas iniciativas administrativas y la praxis médica asumida ilustran un reconocimiento tácito de la profesión como una actividad que debe realizarse por un conjunto de profesionales, facultativos y no facultativos. Sólo debe profundizarse en este ámbito en los diferentes parámetros que utiliza la doctrina para distinguir entre las relaciones horizontales y verticales en el contexto del trabajo en equipo. Ello como primer paso para la concreción del ámbito de aplicación o alcance del principio de confianza, esto es, como fundamento para establecer criterios generales en relación con la extensión de hasta dónde puede confiar un sujeto en la correcta actuación del que con él interactúa en el desarrollo conjunto de una actividad. Hasta dónde tiene que llegar la atención y el cuidado de cada uno de los integrantes del equipo como pauta para la solución de la genuina problemática de la responsabilidad por trabajo en equipo.

En el marco de esta indagación también se entrevistaron cuatro cirujanos con 26 años como especialistas y 30 ańos de servicios. Estos manifestaron no conocer el contenido y alcance del principio de confianza. En un primer momento basaron sus respuestas en la confianza del paciente hacia el médico, expresión de una visión anclada aun en el modelo paternalista de la relación médico-paciente. También se refirieron a los valores que significa el confiar en una persona, de manera que no pudieron ofrecer una respuesta acertada sobre el principio. Cuando le fue explicado su contenido y alcance consideraron de forma unánime que en general les estaba vedado confiar, y que en su condición de especialistas que lleva la jerarquía de la operación, deben estar pendientes del más mínimo detalle (v.gr., cantidad de personas en el salón, si todos tienen el nasobuco, si la puerta está cerrada, aun cuando estas sean responsabilidades de la enfermera). Sin dudas esa situación duplica el estrés inherente a las intervenciones quirúrgicas pero alegan que son el rostro del equipo médico que se conforma para la ejecución de la intervención quirúrgica. Ellos son, dicen con profunda convicción, los que se entrevistan antes de la operación con el paciente y sus familiares y son quienes lo harán después para comunicar la eficacia o no del acto médico.

Todos definieron lo que consideraban por equipo médico aunque resultaron más precisos al explicar su integración. También señalaron que es el cirujano que realizará la intervención quien se considera per se el jefe del «Team Quirúrgico». Sin embargo, son los respectivos jefes inmediatos del resto del personal médico o paramédico quienes determinan, según la programación quirúrgica, la designación de cada integrante en sus respectivas áreas de competencias. No existe posibilidad de que el jefe de equipo seleccione a sus miembros e incluso puede conocerlos el día anterior a la intervención. Con respecto a la existencia de normas que delimiten las funciones y responsabilidades de los integrantes del equipo médico, opinan que aún existen muchas lagunas en este sentido y asumen lo que conocen por su experiencia profesional trasmitida de una generación a otra.

Como se advierte hasta aquí, resulta indudable que en relación a los conceptos trabajo en equipo, división de funciones y principio de confianza no se tienen en este escenario todos los conocimientos e 
instrumentos normativos. Sin embargo, la actividad médica en la contemporaneidad tiende a depender en muchas ocasiones de relaciones de trabajo en equipo. Esta situación, en la eventualidad de presentarse alguna imprudencia que desemboque en lesión para la vida o la salud del paciente, condiciona que la responsabilidad se diluya y sea difícilmente individualizable. A la sazón, resulta vital que estén bien acotados los ámbitos competenciales de cada miembro del equipo, esto es, sus funciones y deberes. Sólo así se contribuirá a determinar la concreta responsabilidad penal de cada uno de ellos con el auxilio del principio de división del trabajo y el principio de confianza. Sólo así el juez, como heraldo de la justicia, contará con las herramientas dogmáticas y normativas, para dilucidar con exactitud sobre quién o quiénes de los que conforman el equipo recaerá la responsabilidad penal.

En efecto, la idea de introducir pautas para la utilización del principio de confianza como herramienta dogmática se orienta a la necesidad de facilitar la apreciar de esta institución en el ordenamiento y la praxis judicial cubana asociada a la determinación de la responsabilidad médica. Y es que la creciente intervención de varios profesionales, el reparto de tareas y la asunción de deberes en el ámbito médico necesariamente exige transitar por la confianza entre colegas competentes, con roles asignados para poder desarrollar el acto médico. De lo contario, coincidiendo con ENGISCH se volvería inviable la actividad de estos profesionales en estos supuestos. ${ }^{101}$ Tales pautas deben enfocarse en dos direcciones: en atención a los presupuestos generales de la responsabilidad médica y atendiendo a la apreciación de los presupuestos del principio de confianza; de tal suerte que formen un todo único donde cada pauta vista de manera individualizada se integre armónicamente en un pensar lógico que conduzca a una solución racional y efectiva en la búsqueda de la verdad.

En lo que se refiere aquí a las pautas relativas a la apreciación del principio de confianza se opta por su dimensionamiento en tres órdenes: teórico, normativo y metodológico. En el orden teórico se propone asumir que el principio de confianza en cuanto límite de la responsabilidad penal no es más que la discusión en torno al alcance de los deberes que pesan sobre cada uno de los participantes en la actividad en equipo. En consecuencia, se entenderá que en su forma más general el principio de confianza postula que quien se comporta debidamente en el contexto de una actividad conjunta puede confiar en que los demás también lo hagan, siempre y cuando no existan indicios concretos para suponer lo contrario.

En el orden normativo se propone adoptar una cláusula en la Parte General del Código Penal sobre el principio de confianza, que podría redactarse del siguiente modo: "cada participante en una actividad puede confiar en que la actuación del resto de los intervinientes será correcta, de tal modo que sólo cuando existan motivos fundados para desconfiar en la conformidad a cuidado de la actuación de los terceros, podrá dejar de invocarse dicha presunción por el resto de los intervinientes".

101 Como se citó en: Maraver Gómez, «El principio de confianza en el Derecho Penal. Un estudio sobre la aplicación del principio de autorresponsabilidad en la teoría de la imputación objetiva», $99 \mathrm{~s}$. 
En el orden metodológico se propone: a) Verificar la actuación bajo los postulados de un equipo médico, b) comprobar que es posible la detección en el reparto médico de funciones, de la actuación imprudente de uno o varios profesionales, c) determinar los respectivos ámbitos competenciales de cada uno de los participantes en la actividad médica, e) verificar el cumplimiento de los presupuestos y límites para la apreciación del principio de confianza.

\section{CONSIDERACIONES FINALES}

El principio de confianza surgió en la jurisprudencia alemana para limitar la responsabilidad por imprudencia en el ámbito del tráfico viario, en oposición a la excesiva previsibilidad y evitabilidad con la que se valoraban las conductas que se presumían imprudentes. No obstante, su propia concepción sirvió de base para que fuera apreciada esta institución jurídica en otras esferas del sector social, como es el caso del ámbito médico, donde opera como resultado de la diversidad de especialidades y el reparto de tareas y funciones que genera una constante actividad en equipo. En este escenario opera la división y delegación de funciones entre los integrantes y se origina un entramado de relaciones verticales y horizontales que deben poder distinguirse. Así, con el tiempo, este principio alcanza un especial protagonismo a la hora de dirimir responsabilidades penales en actividades profesionales peligrosas cuya ejecución se organiza en torno al principio de organización del trabajo.

En su forma más general el principio de confianza afirma que quien se comporta debidamente en supuestos de actuación conjunta puede confiar en que otros también lo hagan, siempre y cuando no existan indicios concretos para suponer lo contrario. Su valor reside en permitir establecer la amplitud del cuidado que le corresponde observar a un partícipe en una actividad conjunta y, en concreto, si este ha de abarcar la actuación de terceros. Es por ello que, como principio general, se puede tener en cuenta como criterio interpretativo dentro de la teoría jurídica del delito cuando se trata de desvalorar jurídico-penalmente conductas interrelacionadas, entrelazadas o cuya peligrosidad depende del comportamiento de terceras personas.

Sin embargo, mientras la doctrina y la jurisprudencia internacional debaten y aplican los criterios que se van elaborando con el correr del tiempo sobre el principio de confianza, nuestra doctrina y jurisprudencia parecen no hacerse eco de tales avances dogmáticos. Resulta común no encontrar, en los manuales de Derecho penal o publicaciones científicas más actuales desarrollos o aplicaciones relativas a esta institución. En igual medida, no es fácil encontrar sentencias que lo apliquen al caso en concreto. Esto es una clara demostración de la orfandad y la necesidad de un debate serio en nuestro ámbito científico y práctico que nos permita seguir evolucionando en la obtención de aquellas herramientas dogmáticas para una mejor aplicación del Derecho.

\section{REFERENCIAS}

- Bernate Ochoa, Francisco. Imputación objetiva y responsabilidad penal médica. Bogotá: Universidad del Rosario, 2010. 
- _. «Responsabilidad penal médica, trabajo en equipo y principio de confianza». Prolegómenos: derechos y valores XI, n.o 21 (junio de 2008): 65-80.

https://doi.org/10.18359/prole.2525

- Choclán Montalvo, Antonio. Deber de cuidado y delito imprudente. Barcelona: Bosch, 1998.

- Contreras, Lautaro. «El principio de confianza como criterio delimitador de la responsabilidad penal de los médicos». Acta Bioethica 25 (2019). https://doi.org/10.4067/S1726-569X2019000100035

- $\quad$ Corcoy Bidasolo, Mirentxu. El Delito imprudente. Criterios de imputación del resultado. Barcelona: PPU, 1989.

- Cuba. Asamblea Nacional del Poder Popular. «Ley No. 41 "Ley de la Salud Pública”,, 13 de julio de 1983.

http://www.parlamentocubano.gob.cu/index.php/documento/ley-de-la-salud-publica/

- Cuba. Consejo de Ministros. «Decreto No. 139 "Reglamento de la Ley de Salud Pública”». Gaceta Oficial Ordinaria No. 12, de fecha 22/02/1988, 4 de febrero de 1988.

http://juriscuba.com/wp-content/uploads/2015/10/Decreto-No.-139.pdf

- Cuba. Ministerio de Salud Pública. «Resolución Ministerial No. 1 "Reglamento General de Hospitales"”, 9 de enero de 2007.

https://files.sld.cu/minsapdocumentos/files/2009/08/reglamento-general-de-hospitales.pdf

- $\quad$ De Vicente Remesal, Javier, y Virgilio Rodríguez Vázquez. «El médico ante el Derecho penal: consideraciones sobre la imprudencia profesional, inhabilitación profesional y el trabajo en equipo». En Universitas vitae. Homenaje a Ruperto Núñez Barbero, editado por Fernando Pérez Álvarez, 145-78. Salamanca, España: Ediciones Universidad de Salamanca, 2007.

- Feijoo Sánchez, Bernardo. «El principio de confianza como criterio normativo de imputación en el Derecho penal: fundamento y consecuencias dogmáticas». Revista de Derecho Penal y Criminología 21, n.o 69 (junio de 2000): 37-76.

- Homicidio y lesiones imprudentes: Requisitos y límites materiales. Zaragoza: Edijus, 1999.

- Fernández Cruz, José Ángel. «El delito imprudente: la determinación de la diligencia debida en el seno de las organizaciones». Revista de Derecho XIII (2002): 101-21.

- Gómez Rivero, María del Carmen. La responsabilidad penal del médico. Valencia: Tirant lo Blanch, 2003.

- Gracia, Diego. Ética y vida No 2: Bioética Clínica. Santa Fé de Bogotá: Editorial El Búho, 1998. 
- _. «Introducción a la bioética médica». Boletín de la Oficina Sanitaria Panamericana 108, n.o 5 y 6 (junio de 1990).

- Hava García, Esther. La imprudencia inconsciente. Granada: Comares, 2002.

- _ La imprudencia médica. Valencia: Tirant lo Blanch, 2001.

- Jescheck, Hans Heinrich, y Thomas Weigend. Tratado de Derecho Penal Parte General. Traducido por Miguel Olmedo Cardenete. 5a edición, Renovada y ampliada. Granada: Colmares, 2002.

- Jorge Barreiro, Agustín. La imprudencia punible en la actividad médico-quirúrgica. Madrid: Tecnos, 1990.

- _. «Nuevos aspectos de la imprudencia jurídico-penal en la actividad médica: la culpa en el equipo médico-quirúrgico». En Responsabilidad del personal sanitario (Actas del Seminario conjunto sobre la responsabilidad del personal sanitario celebrado en Madrid los días 14, 15 y 16 de noviembre de 1994). Madrid: Consejo General del Poder Judicial, 1995.

- Lázaro, José, y Diego Gracia. «La nueva relación clínica», 2003. https://docenciabasurto.osakidetza.net/pluginfile.php/9595/mod_folder/content/0/ Nueva\%20relacion\%20clinica.pdf?forcedownload=1

- «Ley 41/2002, de 14 de noviembre, básica reguladora de la autonomía del paciente y de derechos y obligaciones en materia de información y documentación clínica». «BOE» núm. 274 (BOE-A-2002-22188), 15 de noviembre de 2002. https://www.boe.es/buscar/pdf/2002/BOE-A-2002-22188-consolidado.pdf

- Lombana Villalba, Jaime. Derecho Penal y responsabilidad médica. Colombia: Biblioteca Jurídica Diké, 2010.

- $\quad$ Luzón Peña, Diego-Manuel. Curso de Derecho Penal Parte General. 3ra reimpresión. Vol. I. Madrid: Editorial Universitas, S.A., 2004.

- Maraver Gómez, Mario. «El principio de confianza en el Derecho Penal. Un estudio sobre la aplicación del principio de autorresponsabilidad en la teoría de la imputación objetiva». Tesis doctoral, Universidad Autónoma de Madrid, 2007.

- - - El principio de confianza en el Derecho penal. Un estudio sobre la aplicación del principio de autorresponsabilidad en la teoría de la imputación objetiva. Cizur Menor: Civitas, 2009.

- Martínez Gómez, Jesús Armando. «Naturaleza jurídica de la relación médico-paciente. Estado de la cuestión en Cuba» Bioética (agosto de 2013): 4-13. 
- $\quad$ Maurach, Reinhart, Karl Heinz Gössel, y Heinz Zipf. Derecho penal Parte general. Formas de aparición del delito y las consecuencias juridicas del hecho. Traducido por Jorge Bonfill Genzsch. 7a edición. Vol. 2. Buenos Aires: Editorial Astrea, 1995.

- Peláez Mejía, José María. «Configuración del "principio de confianza” como criterio negativo de tipicidad objetiva». Revista Prolegómenos Derechos y Valores 19, n.o 37 (junio de 2016): 15-35. doi:http://dx.doi.org/10.18359/prole.1677

- Perin, Andrea. «Estandarización y automatización en medicina: El deber de cuidado del profesional entre la legítima confianza y la debida prudencia». Revista Chilena de Derecho y Tecnología 8, n.o 1 (2019): 3-28. doi:10.5354/0719-2584.2019.52560

- Perín, Andrea. «Imprudencia penal médica. Definición criteriológica de un modelo de imputación deóntico y liberal». En Derecho y medicina defensiva: legitimidad y límites de la intervención penal, 117-47. Bilbao-Granada: Editorial Comares, S.L, 2020.

- $\quad$ Poveda Buitrago, Nilson. Imputación objetiva, acciones a propio riesgo y responsabilidad penal médica en Colombia. Bogotá: Grupo Editorial Ibáñez, 2014.

- Ramírez Collejo, Yeline, y Ángel Antonio Blanco Fonseca. «La exigencia de responsabilidad penal en la actividad médica bajo el principio de confianza». En Abogacía y Derecho: Gestión de conflictos jurídicos, I. Parte. Derecho y litigios penales:20-40. La Habana: Ediciones ONBC, 2012.

- República de Cuba. Ministerio de Salud Pública. «Resolución No. 458», 30 de noviembre de 2019. http://legislacion.sld.cu/index.php?P=FullRecord $\& I D=156$

- Risicato, Lucia. L'attività medica di équipe tra affidamento e obblighi di controllo reciproco. L'obbligo di vigilare come regola cautelare. Torino: Giappichelli, 2013.

- Rivera Fernández, Manuel. La responsabilidad médico-sanitaria y del personal sanitario al servicio de la administración pública. Valencia: Práctica del Derecho, 1997.

- $\quad$ Rivero García, Danilo. Ley de Procedimiento Penal, Ley no. 5 de 13 de agosto de 1977 (Anotada y concordada con las Disposiciones del CGTSP). 2a edición. La Habana: Ediciones ONBC, 2012.

- Rivero García, Danilo, y María Caridad Bertot Yero. Código Penal de la República de Cuba Ley No. 62/87 (Anotado con las Disposiciones del CGTSP). 3a edición.

La Habana: Ediciones ONBC, 2017.

- Rodríguez Vázquez, Virgilio. «La delimitación de la responsabilidad penal en el equipo médico-sanitario. Operatividad del principio de confianza ante la división del trabajo sanitario». Accedido 21 de diciembre de 2017. http://www.aeds.org/congreso/congresos-aeds/ponencias/Virgilio\%20Rodriguez\%20 Vazquez.pdf 
- - Responsabilidad penal en el ejercicio de actividades médico-sanitarias. Criterios para delimitar la responsabilidad en supuestos de intervención conjunta de los profesionales sanitarios. Madrid: Marcial Pons, 2012.

- $\quad$ Romeo Casabona, Carlos. El médico y el Derecho penal I. La actividad curativa (Licitud y responsabilidad penal). Barcelona: Bosch, 1981.

- Romeo Casabona, Carlos María. El Médico y el Derecho Penal. Vol. I. 2 vols. Santa Fe: Rubinzal-Culzoni, 2011.

- $\quad$ Roxin, Claus. Derecho Penal Parte General. Fundamentos. La estructura de la teoría del delito. Traducido por Diego-Manuel Luzón Peña, Miguel Díaz y García Conlledo, y Javier De Vicente Remesal. 2.a ed. Vol. I. España: Civitas, S. A., 1997.

- Silva Sánchez, Jesús María. Medicinas alternativas e imprudencia médica. Barcelona: José María Bosch Editor, 1999.

- _ _ _Aspectos de la responsabilidad penal por imprudencia de médico anestesista. La perspectiva del Tribunal Supremo». DS 2 (diciembre de 1994): 41-58.

- Vallejo Jiménez, Geovana Andrea. «Responsabilidad penal sanitaria: problemas específicos en torno a la imprudencia médica». Tesis doctoral, Universidad de León, 2012. https://buleria.unileon.es/bitstream/handle/10612/2217/tesis_e4242b.pdf?sequence=1

- Villacampa Estiarte, Carolina. Responsabilidad penal del personal sanitario. Atribución de responsabilidad penal en tratamientos médicos efectuados por diversos profesionales. Pamplona: Aranzadi, 2003.

- Zaffaroni, Eugenio Raúl, Alejandro Alagia, y Alejandro Slokar. Derecho Penal: parte general. 2a edición. Buenos Aires, Argentina: Ediar Sociedad Anónima Editora, Comercial, Industrial y Financiera, 2002.

RECIBIDO: 06/02/2021

APROBADO: 10/05/2021 